\title{
FINANCIAMIENTO E INVERSIÓN PÚBLICA EN LA ARGENTINA EN UN PERIODO DE TRANSICIÓN, 1900-1935. UN ENFOQUE GENERAL Y DOS ESTUDIOS DE CASO *
}

\section{ANDRÉS MARTÍN REGALSKY CONICET-ITDT}

Universidad Nacional de Tres de Febrero ${ }^{a}$ Universidad Nacional de Luján

ELENA SALERNO

Universidad Nacional de Tres de Febrero ${ }^{b}$

Public Finance and Investment in Argentina During a Transition Period, 1900-1935. A General Overview and Two Case Studies

\begin{abstract}
Between 1900 and 1935, the Argentine economy experienced important changes. Strongly specialized at first in the exportation of primary goods to European markets, the economy gradually turned to import substitution for the internal market. This transition was accompanied by increases in the number and scope of the functions performed by the State. In this paper we approach this evolution with an analysis of public investment in two critical areas: railways and water and drainage works, both of which resulted in the formation of the first public enterprises. Other aspects of public finances are also examined here: the evolution and structure of tax collection and public debt, both of which experienced an ever increasing complexity and scope.
\end{abstract}

Keywords: finance, public investmente, railways, water and drainages works

JEL Classification: N46, N16

* Received 04/16/2008. Accepted 04/03/2009.

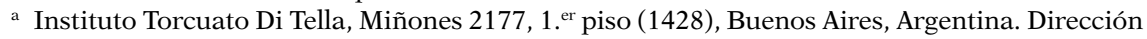
electrónica: regalsky@utdt.edu.

b Instituto de Estudios Históricos, Los Aromos 6231 (1684), Ciudad Jardín del Palomar, Buenos Aires, Argentina. Teléfono: 0054-1-4751-3979. Dirección electrónica: esalerno@untref.edu.ar. 


\section{RESUMEN}

Entre 1900 y 1935, la economía argentina experimentó importantes cambios desde una orientación fuertemente especializada en la exportación de productos primarios a otra más vinculada al mercado interno, incluyendo una incipiente sustitución de importaciones. Esta trayectoria se vio acompañada por el crecimiento en el tamaño y en las funciones desempeñados por el Estado. En este trabajo nos aproximamos a esta evolución a través de un análisis de la inversión pública del Estado nacional en dos áreas críticas, ferrocarriles y obras de saneamiento, que dieron lugar a las primeras empresas públicas. También examinamos otras dimensiones de las finanzas públicas: la evolución y estructura de la recaudación tributaria y del endeudamiento público, que debieron proveer los recursos para estas inversiones y que afrontaron desafíos de una envergadura y complejidad crecientes.

Palabras claves: financiamiento, inversión pública, ferrocarriles, obras sanitarias

En este trabajo nos proponemos abordar el examen de algunos aspectos del comportamiento de las finanzas públicas argentinas entre 1900 y los comienzos de la década de 1930. Se trata de un periodo signado por fuertes cambios en el contexto económico internacional, que implicaron grandes desafíos y perturbaciones para una economía argentina fuertemente orientada inicialmente hacia la exportación de productos primarios a los mercados europeos, y que en el transcurso fue virando hacia una mayor incidencia de las actividades vinculadas al mercado interno, incluyendo una incipiente sustitución de importaciones. Esta trayectoria cambiante se puede contrastar con la continuidad que se observa en otra variable: la de la creciente complejidad de la estructura y funciones que fue ganando el Estado ${ }^{1}$.

La fiscalidad argentina de este periodo presenta una combinación de rasgos de cambios y permanencias en relación a los parámetros con los que venía funcionando desde el siglo XIX. Desde lo que aparecía como un intento de adaptarse a las nuevas condiciones sin cambiar demasiado sus bases, se devendrá al final del periodo en algunas transformaciones significativas, reveladoras de la transición hacia un nuevo paradigma.

\footnotetext{
${ }^{1}$ El papel del sector público ha sido tradicionalmente destacado en los análisis de los procesos de modernización y desarrollo económico. Véanse los textos clásicos de Tilly (1975) y Bouvier (1978) sobre la experiencia europea, y, para el caso latinoamericano y argentino, Cibotti y Sierra (1970) y Oszlak (1982). Un trabajo pionero sobre la acción fiscal en los comienzos de la modernización argentina es el de Marichal (1988b, 89-124). Una sugestiva visión comparativa sobre el sector público en Argentina, Brasil y México, en un periodo que coincide parcialmente con el de este trabajo, en Díaz Fuentes (1993, 1994 y 1999). Sobre el creciente papel del Estado y del gasto público, sobre todo en países de economía abierta y con alta vulnerabilidad externa, véase Gemmell y Morrissey (2005, pp. 131-144).
} 
En este trabajo nos detendremos en algunas variables del gasto y la inversión pública, a través del examen de dos casos de características disímiles pero de importancia crítica en el proceso de modernización y desarrollo en curso, en tanto constitutivos de la infraestructura básica requerida para dicho proceso: los ferrocarriles y las obras de provisión de agua y saneamiento urbano ${ }^{2}$. En ambos sectores las inversiones públicas venían desarrollándose desde el último tercio del siglo XIX, en un caso (ferrocarriles) favoreciendo la conectividad de las áreas más alejadas del interior del país, y en el otro asegurando las condiciones sanitarias en la propia capital de la república. En la medida en que condujeron a la creación de las primeras reparticiones estatales autónomas, en 1910 y 1912 respectivamente, puede considerarse que estas inversiones inauguraron el camino hacia un nuevo modelo de Estado, mucho antes de la época en que el Estado empresario estaba llamado a imperar ${ }^{3}$.

Asimismo examinaremos otras dimensiones de las finanzas públicas necesarias para entender cómo se financiaron estos emprendimientos: la evolución y estructura de la recaudación tributaria, objeto de permanentes polémicas pero que sólo aportará novedades hacia el final del periodo, y la de la deuda pública, de una envergadura y complejidad crecientes. Es nuestra hipótesis que las fuentes de tributación, aun siendo en buena medida «tradicionales», tuvieron un dinamismo apropiado mientras duró la fase de auge agroexportador, y en la fase siguiente pudieron - por su composición «híbrida»- sostener las nuevas acciones del Estado y hasta absorber o mitigar algunas de las remezones externas. A ello se sumaba una estructura de endeudamiento inicialmente típica de los tiempos del patrón oro, que luego iría virando a otra más flexible (y por momentos caótica), en la que el mercado interno y los instrumentos de corto plazo tendrían un papel destacado.

Este trabajo se basa principalmente en el corpus de fuentes constituido por las Memorias de la Contaduría General de la Nación, un minucioso compendio de las rendiciones de todas las cuentas públicas que permite un análisis de conjunto y pormenorizado del gasto, así como de los ingresos y del endeudamiento. Cambios en la organización del material, así como una creciente complejidad a partir de 1914 por la acumulación de partidas sin gas-

${ }^{2}$ Sobre la importancia de las inversiones en infraestructura en el largo periodo histórico que comienza hacia mediados del siglo XIX y concluye en las entreguerras, y el papel de los actores públicos y privados, véase Foreman-Peck y Millward (1994), Giuntini, Hertner y Núñez (2004) y Millward (2005), así como Eichengreen (1995) y Wilkins para la etapa previa a 1914 y en relación con la inversión extranjera.

${ }^{3}$ El otro caso relativamente temprano es el del petróleo, cuya explotación estatal desde 1907 derivó en la creación de una institución autónoma (YPF) en 1922. Véase Solberg (1982), y sobre todo, Gadano (2006). Sobre estas nuevas corporizaciones del Estado empresario, véase Regalsky y Salerno (2008). Para una caracterización del Estado empresario en Europa, véase Ambrosius (1997), Comín y Díaz Fuentes (2004) y, en lo referido a infraestructura, Foreman-Peck y Millward (1994), Millward y Singleton (1995) y Millward (2005). Un análisis pionero del caso argentino en Schvarzer (1979). 
tar, dificultan por momentos su análisis, a lo que debemos agregar las limitaciones de una información remitida a veces con demoras y cierta reticencia por las flamantes administraciones autónomas, y procesada con dificultades por un órgano centralizado que comenzaba a mostrar signos de saturación ${ }^{4}$. De ahí que sea complementada con la consulta de fuentes de las propias reparticiones. No obstante, constituye un observatorio privilegiado para medir comparativamente la acción del Estado en estos sectores en relación al gasto y la inversión total.

\section{1. ¿TRADICIONAL O MODERNA? LA HACIENDA PÚBLICA ARGENTINA EN UN PERIODO DE TRANSICIÓN: INGRESOS, GASTOS Y ENDEUDAMIENTO}

\subsection{Los dilemas de la estructura tributaria y la dinámica del gasto y el déficit fiscal}

La literatura clásica sobre los sistemas tributarios y el desarrollo económico suele hacer hincapié en los cambios de estructura impositiva que han acompañado el tránsito a la modernidad. Así, una estructura basada en impuestos indirectos, si bien renovadora frente a la tributación de «antiguo régimen", debía ceder lugar a otra mayormente fundada en los impuestos directos para que el Estado pudiera abordar los desafíos del crecimiento y desarrollo propios del siglo $\mathrm{xX}^{5}$. Algunos autores comenzaron a ver luego que los impuestos indirectos podían cumplir un papel más eficaz (aunque ciertamente mucho menos equitativo) en esta tarea, preservando la recaudación de los peligros de la evasión, hasta que el Estado desarrollara las herramientas más adecuadas ${ }^{6}$. En el caso argentino, durante buena parte del periodo estudiado la estructura tributaria del Estado nacional se mantuvo casi sin cambios, asentada principalmente en los impuestos indirectos, y sobre todo en los vinculados al comercio exterior. Esto ha sido considerado un signo del carácter «tradicional» de la fiscalidad argentina, típico de la hacienda pública del siglo XIX, diseñada sobre bases estrechas y ajustada a la concepción de un Estado "mínimo» en cuanto a sus intervenciones en el orden económico y social ${ }^{7}$. Las limitaciones de la base tributaria estarían

${ }^{4}$ Estas dificultades ayudarían a explicar el llamativo poco empleo que se ha hecho de esta fuente por parte de los investigadores.

5 Hinrichs (1967, pp. 87-129) y Musgrave (1969).

6 Una literatura orientada a la problemática de los actuales países en desarrollo da cuenta de estas consideraciones. Newbery (1987), Tanzi (1987), Burgess y Stern (1993).

7 Pro Ruiz (2005), y sus referencias a las críticas de un observador europeo contemporáneo, Gaston Jèze. Véase también Comín y Díaz Fuentes (2006), sobre el peso inercial de las tradiciones latinoamericanas del siglo XIX, en oposición a un modelo europeo más basado en los impuestos personales. 
así en la base de los recurrentes ciclos de endeudamiento, crisis financiera y reestructuración de la deuda en los que quedaba envuelto el Estado. En el gráfico 1 puede apreciarse una participación declinante de las rentas generales en el producto bruto interno, con una fuerte caída a partir de 1914 y una recuperación en la década de 1920, que no llega a igualar los niveles de preguerra $^{8}$.

Ahora bien, visto desde otro ángulo, el de una economía en la que el comercio exterior constituía la variable más dinámica, esta estructura tributaria distaba de ser tan estrecha e inelástica como la imagen del modelo europeo decimonónico podría sugerir. En efecto, la trayectoria de la recaudación tributaria en los primeros decenios del siglo muestra un destacable dinamismo. Hacia 1900 la liquidación de la dura crisis de 1890, un proceso penoso en el plano fiscal como lo había sido en el de la moneda y de la deuda pública ${ }^{9}$, apenas acababa de cerrarse. Sin embargo, ya entonces las rentas públicas, medidas en pesos oro, superaban en un 67 por cien los niveles máximos alcanzados en 1889, a pesar del impacto de la crisis y la depreciación del signo monetario. En esa misma moneda (pesos oro) los ingresos siguieron aumentando, en un 150 por cien entre 1900 y 1913, y en un 100 por cien entre ese año y 1928. Medidos en pesos papel de valor constante, los aumentos resultaban de una magnitud mucho menor, 73 y 50 por cien respectivamente, aunque todavía superior a la del aumento demográfico en ese periodo (ver gráfico 1 y cuadro A1 del Apéndice) ${ }^{10}$.

Fue sin duda el estallido de la Primera Guerra Mundial el que abrió paso a uno de los periodos más traumáticos en la historia fiscal, por la fuerte caída que provocó en el nivel de ingresos, de un 30 por cien en términos nominales y un 50 por cien a valores constantes hasta fines de 1917, y en relación a 1913. Esta caída, acarreada por el colapso de las importaciones (que aportaban más de la mitad de la recaudación fiscal), dio inicio a un periodo de intensas discusiones y cuestionamientos a la estructura tributaria vigente. La gran volatitilidad de los ingresos públicos ante las conmociones externas ${ }^{11}$ era uno de los aspectos más notados, que se combinaba con la emergente discusión sobre los principios de equidad que una tributación directa, más «moderna», debía ayudar a instaurar. Sucesivos proyectos de reforma

8 Los datos del PBI, en CEPAL (1958, pp. 3-4). Esta igualación sí ocurre, hacia 1928-1929, si se considera la serie de PBI de Roberto Cortés Conde (ver el cuadro A1). El comportamiento más dinámico de los gastos, y el consecuente déficit fiscal, pueden apreciarse también en el gráfico 2.

9 Cortes Conde (1989), Ferns (1966) y Marichal (1988a).

10 Los datos de precios, en Cortés Conde (1979, p. 226), Bunge (1920, pp. 253-261) y Díaz Alejandro (1991, tablas S3 y S4). Otros índices en Della Paolera y Taylor (2003, pp. 276-277 y cd). Los de población, en Cavallo, Mundlack y Domenech (1986, p. 118) y Ferreres (2005, pp. 445-453).

11 Conceptualizado por O'Connell (1984, pp. 481-486), en términos de inestabilidad y vulnerabilidad externas, el problema de la volatilidad ha venido generalmente asociado en la literatura económica al comportamiento macroeconómico de los países «emergentes» y las bruscas alteraciones cambiarias que lo acompañaban, y sobre todo, a las características intrínsecas de los mercados de capitales. Aghion, Banerjee y Piketty (1999), IMF (1984) y Peters (1996). Ver el gráfico A1. 


\section{GRÁFICO 1}

EVOLUCIÓN DE LAS RENTAS GENERALES, RECURSOS TOTALES Y GASTOS TOTALES DEL SECTOR PÚBLICO NACIONAL, 1900-1935 (en porcentaje del PBI)

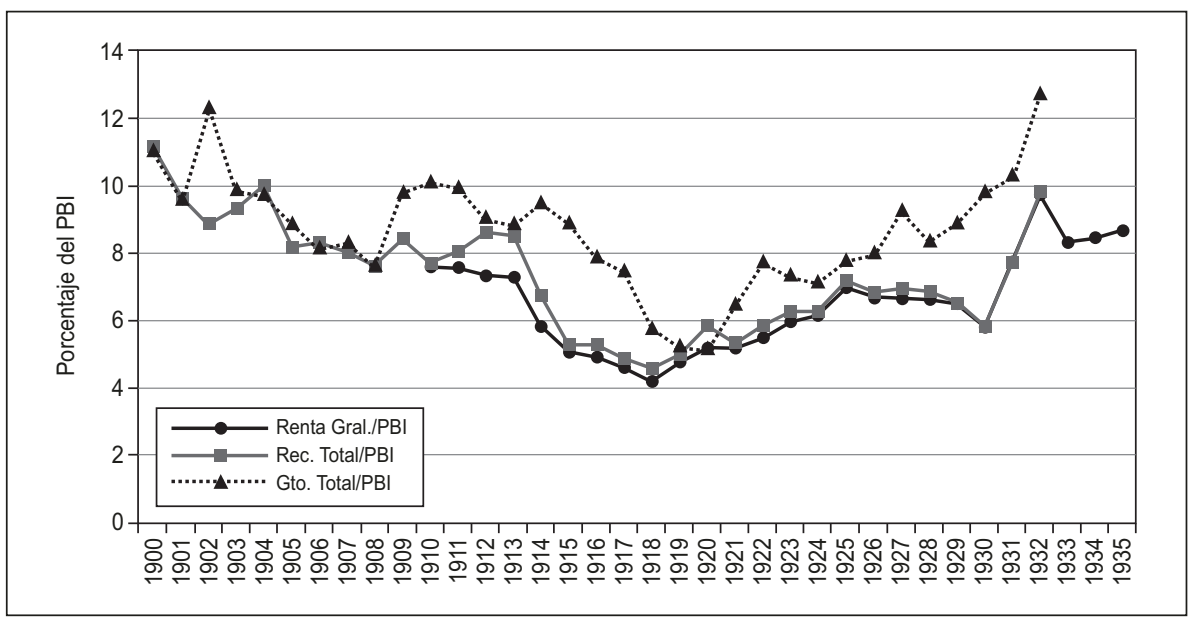

Fuente: Ver cuadro A1 del Apéndice.

tributaria y de creación de un impuesto a las rentas, presentados por los presidentes Yrigoyen (1916-1922) y Alvear (1922-1928), fueron discutidos en el Congreso en 1918, 1923 y 1924, aunque sin lograr el apoyo necesario. Si en 1918 la modestia de la reforma propuesta pudo contribuir a que no se considerase imprescindible su implementación —en cambio se aprobó un impuesto a las exportaciones ganaderas que aportó una suma significativa-, en los dos casos siguientes fue la compleja red de intereses afectados la que contribuyó a bloquear la iniciativa, en momentos en que la coyuntura externa daba señales de un retorno a la normalidad ${ }^{12}$.

En todo caso, lo que se ocultaba tras esta discusión es que una cierta «revolución silenciosa» había tenido lugar en la estructura impositiva después de 1890 a través de la instauración de una amplia gama de impuestos «internos» que, aun siendo también indirectos, aportaban un componente de estabilidad frente a las adversas coyunturas externas ${ }^{13}$. Estos impuestos,

12 Los proyectos de reforma han sido analizados exhaustivamente por Caravaca (2008), Heredia (2008) y Sánchez Román (2009). Para una comparación con los alineamientos sociales que se produjeron en algunos países europeos puede verse Daunton (1996, pp. 169-178) y Webber (1986, pp. 341-352).

13 El papel de estos impuestos «internos» sobre el consumo de productos específicos —y sólo mucho después, sobre las ventas - ha sido señalado por diversos autores como un eslabón intermedio en el proceso de modernización tributaria, respecto de los que gravaban el comercio exterior. Hinrichs (1967), Newbery (1987), Tanzi (1987) y Burgess y Stern (1993). También se ha señalado su papel en la evolución impositiva americana: Musgrave y Musgrave (1992, pp. 390-392). 
creados en lo peor de la crisis para afrontar el cumplimiento de los compromisos externos, fueron claves en la recuperación que permitió, hacia 1895, alcanzar el nivel de recaudación - medido en metálico - previo, y sacar partido del dinamismo del mercado interno ${ }^{14}$. De un 5,8 por cien en 1895 , su participación en las rentas generales siguió ascendiendo hasta llegar al 17,4 por cien en 1910-1914 (cuadro A2 del Apéndice). Durante la guerra aumentaron su aporte hasta el 24,4 por cien en 1917, en tanto los del comercio exterior bajaban el suyo desde un 61 a menos del 46 por cien, y descendían en valores absolutos a la mitad o a la tercera parte de su valor previo (según se consideren en pesos corrientes o de valor constante). Los impuestos internos (junto a los directos), por el solo hecho de sostener sus niveles previos, contribuyeron en esos años a morigerar la caída.

A partir del piso mínimo alcanzado en 1917, las rentas generales comenzaron en la posguerra un proceso de recuperación. Esta recuperación, si bien no alcanzó para retomar los niveles de participación en el PBI registrados en la preguerra, puede considerarse significativa cuando se toman las cifras absolutas. A valores nominales permitió recuperar los niveles de 1913 hacia 1919 y superarlos en un 77 por cien hacia 1928. En pesos de valor constante la recuperación fue más lenta. Recién en 1923 se retomaron los niveles de 1913, y en 1928 se los superaba en un 33 por cien. En esta trayectoria, si al principio jugaron algún papel los flamantes impuestos a la exportación (véase el gráfico 2), el factor preponderante volvió a ser la tributación sobre las importaciones, que en sucesivos peldaños (1920, 1923 y 1925) logró alcanzar y superar los valores de preguerra. Durante varios años la falta de actualización de los aforos sobre los que se aplicaba el gravamen, impidió reflejar en los guarismos de ese impuesto el alza de los precios. La fuerte actualización dispuesta en 1923 y el reajuste a la baja de los precios de importación después de 1920, llevó a que la recaudación de ese impuesto, lo mismo que las rentas generales, tuvieran en la segunda mitad de esa década un mejor desempeño (cuadro A6 del Apéndice).

Ciertamente, durante este proceso los impuestos internos y los directos volvieron a sus niveles de participación de preguerra, pero en los años de la crisis otra vez ayudaron a compensar el impacto producido por la caída de valores del comercio exterior, particularmente a partir de 1932, cuando se agregaron dos nuevos impuestos a las transacciones y a los réditos (véase gráfico 2 y cuadro A2). Bajo este nuevo impulso, la presión tributaria arrojó valores ascendentes, tanto en términos nominales como reales, en tanto descendía la base imponible del comercio exterior, y aún — hasta 1934- la del PBI ${ }^{15}$.

14 Guy (1979, p. 20).

15 Véase el cuadro A6. Es dable señalar que en 1931, cuando todavía no se habían creado los nuevos impuestos, las rentas generales se habían apuntalado con una serie de rubros extraordinarios, provenientes de los beneficios de cambio que el gobierno se hizo acreditar, y que posibilitaron su aumento en relación a 1930. MCGN (1931, p. 38). 


\section{GRÁFICO 2}

ESTRUCTURA TRIBUTARIA DEL GOBIERNO NACIONAL, 1910-1935

(en millones de pesos corrientes)

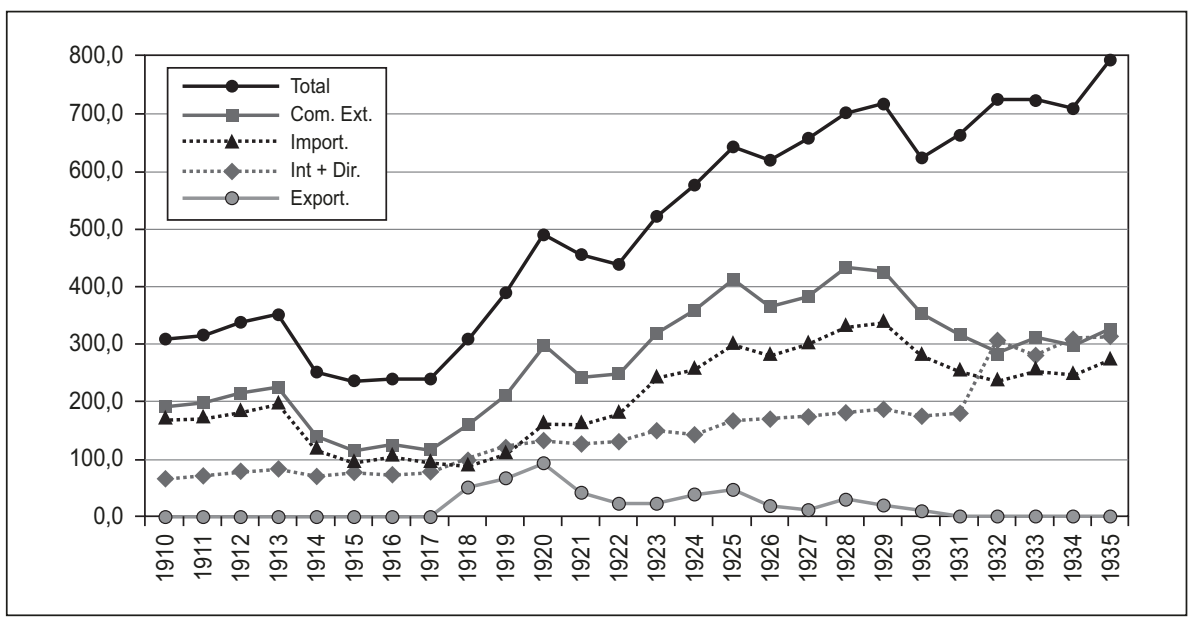

Fuente: Ver cuadro A2 del Apéndice.

El corolario de toda esta secuencia fue la conformación hacia 1935 de una nueva estructura tributaria, que como vemos, no fue creada de una sola vez. En ese último año los ingresos del comercio exterior claramente habían reducido su participación, y se ubicaban por primera vez en torno a un 40 por cien, siendo casi equiparados por la suma de los impuestos directos e internos.

Fue en el marco de esta evolución —plena de avatares— de la recaudación pública que comenzó el ascenso del gasto que desembocaría, en la segunda y tercera décadas del siglo, en los recurrentes déficit fiscales ${ }^{16}$. Hasta 1908 ese ascenso se mantuvo en estrecha correlación con los ingresos. Solo en 1902 hubo puntualmente un aumento extraordinario del gasto que provocó un abultado déficit ( 39 por cien de los ingresos), resuelto en todo caso en el ejercicio siguiente. A partir de 1909, en cambio, el crecimiento del gasto se aceleró abruptamente, generándose hacia 1910 un déficit del 31 por cien, que luego se redujo por la estabilización del gasto (en torno a la cifra de 400 millones de pesos corrientes) y el ascenso de los ingresos en 1912 y 1913 (véase gráfico 3 y cuadro A3).

Durante los años de la guerra, en los que la recaudación bajó ostensiblemente, el nivel de los gastos nominales apenas pudo reducirse: se mantuvo

16 Este ascenso - en términos absolutos- del gasto debe ciertamente matizarse. Como porcentaje de PBI (serie de Cepal) expresa más bien una recuperación que permitió hacia 1930, igualar los niveles máximos de 1909-1911 (o bien superarlos, si se toma la serie de Cortés Conde). 


\section{GRÁFICO 3}

RECURSOS, EROGACIONES Y DÉFICIT DEL GOBIERNO NACIONAL, 1900-1932 (en millones de pesos de 1914)

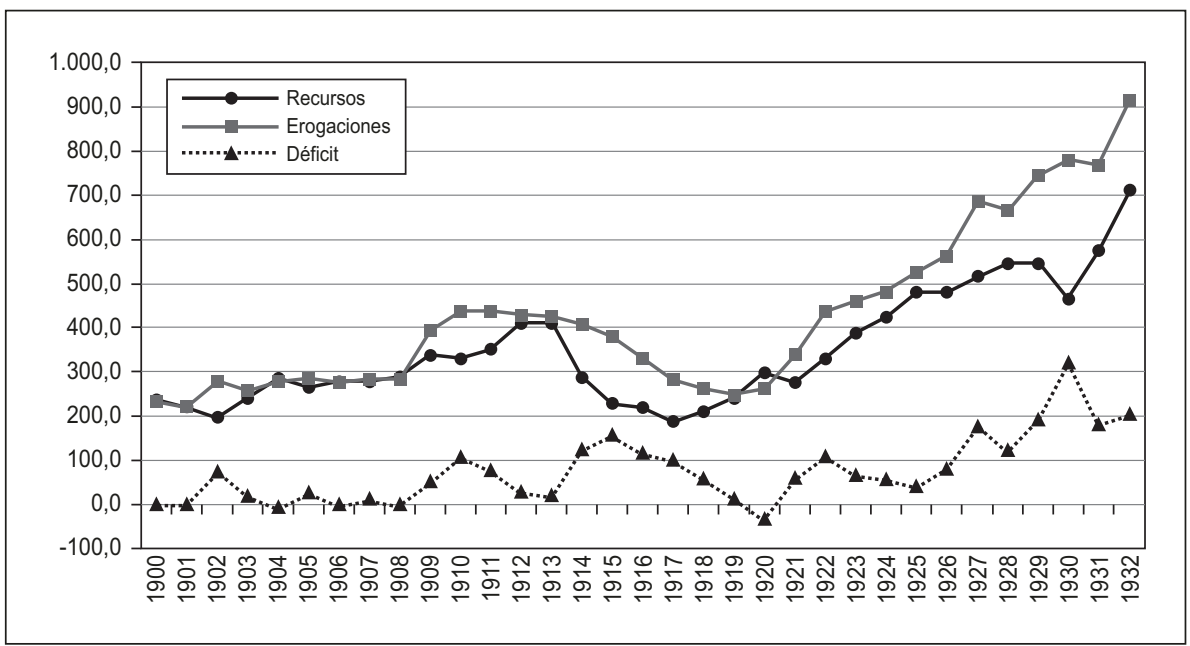

Fuente: Ver cuadros A4 y A5 del Apéndice.

hasta 1919 en torno a los 400 millones de pesos. Esto llevó el déficit fiscal a niveles record: más del 50 por cien de la recaudación (68 por cien en 1915). En rigor, el alza contemporánea de los precios llevó los valores reales del gasto en 1918-1919 a un 40 por cien por debajo del nivel de preguerra. Por otra parte, hacia 1919 la recuperación de los ingresos permitió reducir el déficit fiscal a un mínimo, y en 1920 producir un superávit. Este último año, de fuerte crecimiento de los ingresos nominales (no así de los reales) sobre todo por el aporte de los derechos sobre la exportación, fue el único superávit fiscal que habría de registrarse hasta el final de la serie.

El aparente mejoramiento de la situación fiscal en 1920 (en buena medida favorecido por los precios inflados de posguerra) marcó el punto de partida de una nueva secuencia ascendente del gasto, que no iba a detenerse hasta 1927. Ese año se ubicaba un 120 por cien por encima del nivel de preguerra. Al mismo tiempo, el crecimiento más acompasado e irregular de los ingresos tornó sistemático el déficit fiscal. Sus guarismos registraron dos picos, en 1922 y 1927, equivalentes al 33 y 20 por cien de la recaudación, respectivamente (véase gráfico 3 y cuadro A3).

Aún así, los mayores valores en materia de gasto y de déficit estaban todavía por verse. En 1930, ya bajo plena influencia de la crisis, el gobierno de Yrigoyen continuó la secuencia ascendente de los gastos retomada en el primer año de su segundo mandato (1929) hasta superar la emblemática cifra de los 1000 millones de pesos corrientes, un 150 por cien por encima del 
nivel de preguerra. El déficit, dado que ese año fue el de más bajos ingresos, alcanzó proporciones colosales: 68 por cien de los recursos, similar al de 1915. El derrocamiento de Yrigoyen vino aunado a un plan de ajuste de los gastos, de cepa ortodoxa, que llevó en 1931 a una baja del 16 por cien ${ }^{17}$. No obstante, al año siguiente el gasto volvería a subir y el promedio de esos dos años a nivel nominal fue similar al de 1928-1929. También siguió excediendo a los ingresos, con lo que el déficit distó de ser aventado. Por otra parte, medido en valores constantes, el gasto promedio fue superior al del mismo año 1930, dada la deflación imperante. De esta manera, la continuidad de las tendencias previas resultaba más notable ${ }^{18}$.

\subsection{El financiamiento del sector público: el ascenso de la deuda flotante y del mercado interno}

Si el crecimiento de los gastos tendió a superar desde 1909 al de los ingresos, el déficit concomitante requirió un esfuerzo de financiamiento de proporciones considerables, y que implicó de acuerdo al desarrollo de la coyuntura, diversos desafíos.

Por de pronto, la relación entre gasto, déficit y endeudamiento tuvo un signo cambiante. El primer gran déficit registrado en 1902 no involucró en lo inmediato ninguna operación de crédito, sino la utilización de existencias (el Fondo de Conversión monetaria), que luego habrían de reponerse. La realización de una gran operación de crédito (el empréstito de obras públicas de enero de 1909), proveyó los fondos que alimentaron el crecimiento de los gastos y del déficit público en los dos años siguientes, en vez de ser su resultante. En cambio el segundo empréstito de 1911, cuyo producto ingresó entre 1911 y 1912, permitió cubrir el nuevo deficit que se estaba acumulando a partir de la expansión del gasto generada por la anterior operación de crédito. A partir de 1914, el trastrueque de las condiciones impuesto por el estallido de la Primera Guerra Mundial, al acarrear, entre otros efectos, una fuerte baja de los recursos fiscales, dio lugar a una nueva expansión del uso del crédito para cerrar - ahí sí- la brecha con los gastos. La concertación de empréstitos de largo plazo en las principales plazas financieras internacionales, que ya veía tornándose difícil después de $1911^{19}$, se volvió literalmente imposible, y todo lo que el gobierno pudo fue obtener créditos de corto y mediano plazo. Uno de ellos, por 50 millones de dólares a cinco años, contratado en 1915 en Londres y

17 Díaz Fuentes (1994, pp. 143-145).

18 Algunas revisiones recientes - matizadamente optimistas - sobre los años 1920, convergen en parte con la perspectiva aquí expuesta: Gerchunoff y Aguirre (2006) y Gerchunoff y Salazar (2002). Una interesante discusión metodológica de la evidencia estadística en Salazar (2004).

19 De hecho el empréstito de ese año sólo se pudo colocar entre el público parcialmente, quedando en gran parte en la cartera de los banqueros emisores. Regalsky (2002, pp. 399-407). 
Nueva York, fue la mayor operación internacional de esas características en los tiempos de la Gran Guerra ${ }^{20}$.

En los años siguientes, la gran liquidez del mercado local permitió obtener internamente una parte considerable de los nuevos créditos - y aún reembolsar la mayor parte de los externos- a través de la emisión de letras de Tesorería (gráfico 4 y cuadro A5). La mayor parte de estas letras (tomadas por bancos o particulares) fueron a su turno redescontadas ante el Banco de la Nación Argentina, la gran entidad oficial que por entonces había experimentado el mayor crecimiento en materia de depósitos hasta concentrar la mitad de los correspondientes a la totalidad del sistema ${ }^{21}$.

Así, la deuda flotante, que en 1914 sólo representaba 150 millones de pesos (y mucho menos en los años previos) subió a 580 millones en 1918, para estabilizarse en ese nivel hasta 1921, en que el nuevo programa de obras públicas y la baja simultánea de los ingresos, la empujaron a un nuevo nivel, de 780 millones. Junto con la deuda de los Ferrocarriles del Estado (por entonces contabilizada por separado) y la deuda exigible (las imputaciones impagas), el conjunto del financiamiento de corto plazo superaba en 1923 los 1.000 millones de pesos, y equivalía al 44 por cien de la deuda pública total.

No faltaron entonces proyectos para convertir esa deuda en otra de largo plazo. Las dos principales propuestas, en 1917 y 1923, contemplaban colocar los nuevos bonos entre los bancos del sistema, en un caso a través de una reforma financiera de más vasto alcance ${ }^{22}$. Las condiciones políticas y financieras adversas impidieron entonces su concreción. Mientras tanto, la deuda pública consolidada se mantenía en unos 1.300 millones de pesos papel, apenas por encima del nivel de diez años atrás.

A partir de 1924, la mejoría de la situación financiera internacional permitió el lanzamiento masivo de una serie de nuevos empréstitos sobre el mercado de Nueva York, que consolidaron la deuda flotante en general (series AB-C-D del empréstito de 1924-1925), así como la de los Ferrocarriles del Estado y Obras Sanitarias en particular (empréstitos de 1924 y 1927). También entonces comenzaba a tomar peso la emisión de títulos de deuda interna, en pesos moneda nacional, sobre el mercado local. Hacia 1928 la deuda consolidada se había incrementado más del 70 por cien, hasta los 2.268 millones de pesos papel, mientras la deuda flotante y exigible bajaba a la mitad (véase el cuadro A5 del Apéndice). En los últimos años la situación

${ }^{20}$ La operación, contratada con Baring Brothers de Londres y Morgan y City Bank de Nueva York, se destinaba a financiar los gastos del programa de las obras públicas en curso, particularmente las de provisión de agua y saneamiento. El crédito reemplazaba a otros dos por ocho millones de libras, contratados con Baring y Midland Bank en vísperas de la Guerra. Peters (1932, pp. 79-82).

21 Aparte de los créditos directos que el Banco Nación tenía concedidos a la Tesorería, que lo convertían en el acreedor mayoritario de la deuda de corto plazo del gobierno nacional (véase cuadro A9).

22 Véanse RA (1917, 1923a y 1923b). 
volvió a cambiar. Las emisiones externas cesaron completamente, al menos hasta $1932^{23}$. Las de títulos internos continuaron, aunque su colocación presentó crecientes dificultades, y la deuda flotante y exigible nuevamente vino a cubrir la brecha entre ingresos y egresos, hasta alcanzar en 1931-1932 los 1.200 millones de pesos (un tercio de la deuda pública total) ${ }^{24}$. Esta deuda de corto plazo sería redimida en 1935, cuando la revaluación de las reservas en divisas del flamante Banco Central permitiera una amplia reforma y saneamiento del sistema financiero y bancario (que detentaba, finalmente, una gran parte de los créditos).

Considerando el crecimiento de la deuda pública entre 1900 y 1932, se pueden encontrar tres etapas bien diferenciadas: la primera, hasta 1913, en la que primó el endeudamiento en bonos de largo plazo (deuda consolidada), en pesos oro y sobre los mercados externos — casi el 90 por ciento-; la segunda, hasta 1923, caracterizada por el aumento de la deuda de corto plazo (flotante), principalmente sobre el mercado interno; y una tercera etapa, por el aumento de la deuda consolidada, sobre todo de títulos internos y en papel, acompañado hacia el final por un crecimiento de la de corto plazo (gráfico 4).

\section{GRÁFICO 4}

DEUDA CONSOLIDADA EN ORO Y PAPEL Y DEUDA FLOTANTE Y EXIGIBLE, 1914-1932 (en millones de pesos corrientes)

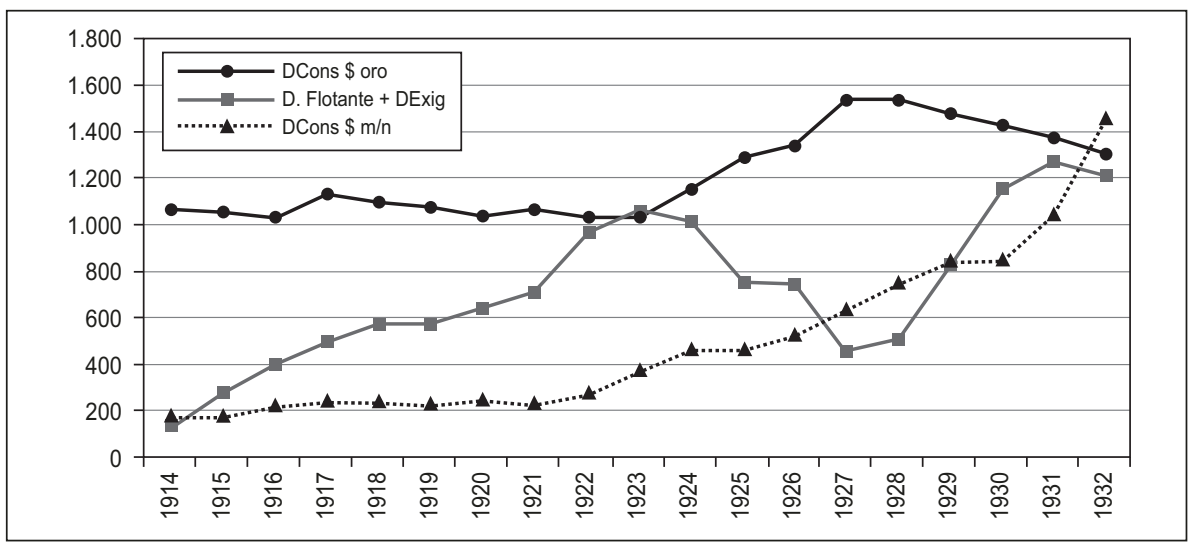

Fuente: Ver cuadro A5 del Apéndice.

23 Los empréstitos de desbloqueo de divisas, en 1933 y 1934, fueron las únicas nuevas emisiones de deuda externa, al tiempo que presentaban la novedad de hacerse en pesos moneda nacional. Sobre este tema O’Connell (1984, pp. 507-508).

24 Uno de los aspectos más llamativos fue el aumento de la deuda exigible —por expedientes impagos- en unos 300 millones de pesos, entre 1929 y 1931, que en parte sería pagada en 1932 con un fuerte adelanto de la Caja de Conversión (véase el cuadro A5 del Apéndice). 
El ritmo de crecimiento del endeudamiento total presentó asimismo divergencias: mientras en el primer periodo (trece años) fue del orden del 17 por cien, en los dos periodos subsiguientes fue mucho mayor, del 84 y 68 por cien, respectivamente (cuadro A10 del Apéndice). Una observación más detallada de la dinámica del endeudamiento permite a su vez subdividir internamente las tres etapas. En la primera, hubo hasta 1908 una reducción neta del endeudamiento, por efecto de las amortizaciones y del retiro de los titulos del Funding Loan de 1891. Entre 1909 y 1913, por el contrario, una serie de emisiones resultaron en un aumento neto de casi el 40 por cien de la deuda consolidada de largo plazo. La segunda etapa presentó tres fases: una de crecimiento rápido hasta 1917 sobre la base de la deuda flotante, externa e interna, otra de estabilización y reabsorción (parcial) del endeudamiento externo hasta 1920, y nuevamente, crecimiento de la deuda flotante (sobre todo interna) hasta 1922/23. En la tercera etapa finalmente, se pueden reconocer dos fases, de 1923 a 1928, en la que el peso de la deuda flotante se redujo, sobre la base de las nuevas emisiones de deuda consolidada, sobre todo en el exterior, y un aumento moderado de la deuda total (18 por cien); y la de 1928-1932, en la que el endeudamiento volvió a basarse en los instrumentos de corto plazo - con importante peso de la deuda exigible y adelantos de la Caja de Conversión-, conjuntamente con la emisión de títulos de la deuda consolidada interna. Ello resultó en un mayor crecimiento de la deuda total - de 41 por cien en cuatro años, o de 31 por cien si se descuentan los bonos aún sin colocar.

Ajustando esos valores por la variación del índice de precios (pesos de valor constante) los resultados son diferentes. El aumento neto del endeudamiento entre 1913 y 1923 (morigerado por la inflación de ese periodo) habría sido del 38 por cien, el de 1923-1932 (potenciado por la deflación de esos años), del 126 por cien, y el del primer periodo (también con alzas de precios) habría sido directamente negativo. En conjunto el aumento de la deuda pública habría sido entre 1900 y 1932 del 143 por cien. En términos de su participación en el PBI, la evolución del endeudamiento muestra una primera fase, hasta 1913, en la que su participación cae del 75 al 25 por cien, fruto de la baja en términos reales del endeudamiento y del aumento del PBI; una segunda fase, de alza moderada hasta 1917 (por el descenso del PBI) y de fuerte caída después (por la licuación que implicó el alza de precios de esos años), que llega hasta a un mínimo de 19 por cien en 1920; una tercera, de alza moderada al principio y luego de lento descenso, que permite retornar a niveles similares a los de la inmediata preguerra, y finalmente, un fuerte alza a partir de 1930, por el aumento del endeudamiento potenciado por la baja de precios y la caída del PBI. La razón deuda/ingresos fiscales mostró una evolución similar aunque más contrastada: un primer momento de caída desde valores próximos a 7 a 1, a menos de la mitad hasta 1913, seguida de un alza que retorna a los niveles iniciales hasta 1917 y una nueva baja que los lleva a 3,5 en 1920. Entre 1920 y 1922 una nueva alza seguida de un lento descenso hasta 1928, y a partir de allí un nuevo aumento, que lleva la razón por encima de 6 


\section{GRÁFICO 5}

EVOLUCIÓN COMPARADA DE LA DEUDA PÚBLICA, LOS INGRESOS PÚBLICOS Y EL PBI, 1900-1932

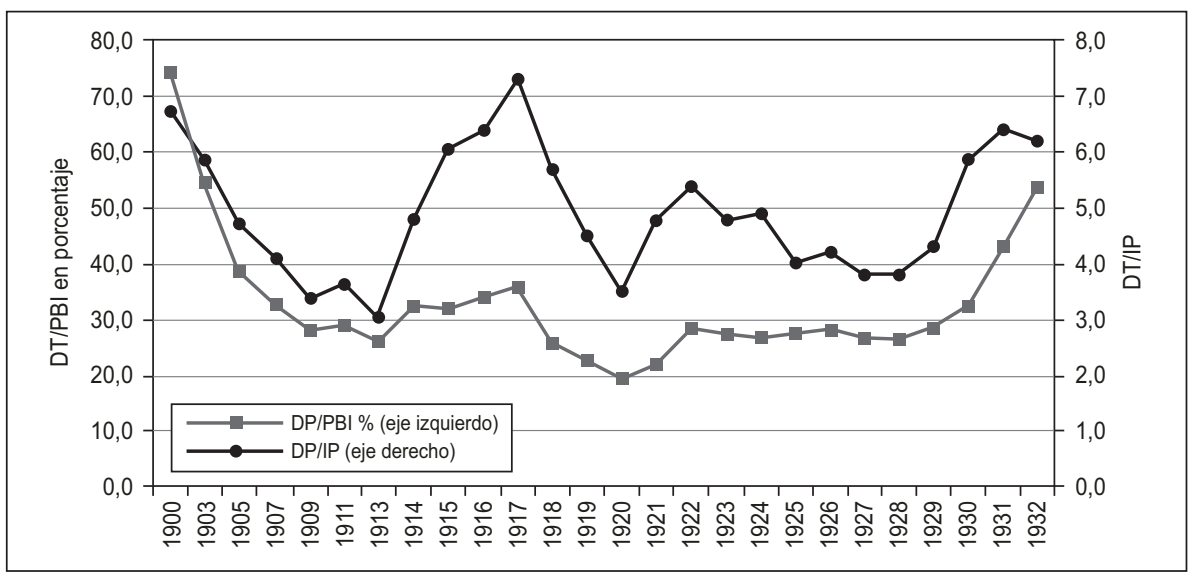

Fuente: Ver cuadros A1, A3 y A5 del Apéndice.

en 1931. Es la mayor fluctuación de los ingresos fiscales, y sobre todo, la abrupta caída de 1914 a 1917, la que explica este comportamiento (gráfico 5).

\section{LA ESTRUCTURA Y EVOLUCIÓN DEL GASTO Y EL DESARROLLO DE LA INVERSIÓN PÚBLICA EN DOS SECTORES CLAVE: LOS FERROCARRILES Y LA PROVISIÓN DE AGUA Y SANEAMIENTO URBANO}

El examen de la composición del gasto puede aportar algunas claves para entender el comportamiento de la fiscalidad y los problemas recurrentes de financiamiento. Al comenzar el periodo los gastos del Ministerio de Hacienda eran los más importantes. Hacia 1900 superaban holgadamente el 40 por cien del gasto público total, y el servicio de la deuda pública y del crédito de corto plazo constituía desde ya el ítem más importante. Su inflexibilidad a la baja implicaba una afectación anticipada de las rentas generales. De ahí los sucesivos proyectos de conversión con los que las autoridades procuraron bajar la carga de intereses ${ }^{25}$. En los años posteriores el nivel quedaría estabilizado y su incidencia en las rentas bajaría paulatinamente hasta un 22 por cien en 1908.

25 Nos referimos al frustrado proyecto de unificación de la deuda, propuesto por Pellegrini en 1901, y la conversión y retiro de bonos de 1905, efectuados por el ministro Terry. Regalsky (2002, pp. 377-389). 
El mayor protagonismo en el aumento de los gastos que es dable observar a partir de 1909 (gráfico 6 y cuadro A4) correspondió en cambio al rubro de las obras públicas. Los gastos del Ministerio de Obras Públicas, sumados a los del flamante presupuesto de Trabajos Públicos, pasaron de una media de 19 millones en 1900-1904, a 101 millones en 1910-1914, con una participación en el gasto total de 24,5 por cien, porcentual muy similar al de la máxima histórica de la década de 1880, que jamás volvería a ser retomada.

Luego de una abrupta retracción durante la guerra, que hizo descender la participación del sector Obras Públicas a la mitad de los guarismos previos, a partir de 1920 volvió a apreciarse una reactivación. Entre 1925 y 1929 el monto destinado a obras y trabajos públicos retomó y superó los niveles de preguerra, con 125 millones de pesos, y, sorprendentemente, lo hizo nuevamente en los años de crisis de 1930-1934, con más de 140 millones. Ciertamente, la participación relativa, del orden del 15 por cien, fue inferior a la del auge de preguerra, pero en 1929 y 1930 (el último bienio yrigoyenista) se alcanzaron guarismos del 21 por cien, muy próximos a los de 19101914. En rigor, los datos anuales nos indican que luego hubo un fuerte recorte, que llevó a la inversión pública al 10 por cien del gasto total en 1932, pero enseguida se recuperaron -al menos- los niveles nominales previos de 1927-1928. Parece razonable postular entonces la continuidad de un programa de inversiones públicas, que se habría iniciado antes de la guerra bajo el régimen conservador y retomado por el radicalismo en los años 1920, y que habría sobrevivido incluso al drástico cambio de régimen que supuso el de-

\section{GRÁFICO 6}

EVOLUCIÓN DEL GASTO EN OBRAS PÚBLICAS, FERROCARRILES Y OBRAS SANITARIAS, 1900-1934 (en miles de pesos de 1914)

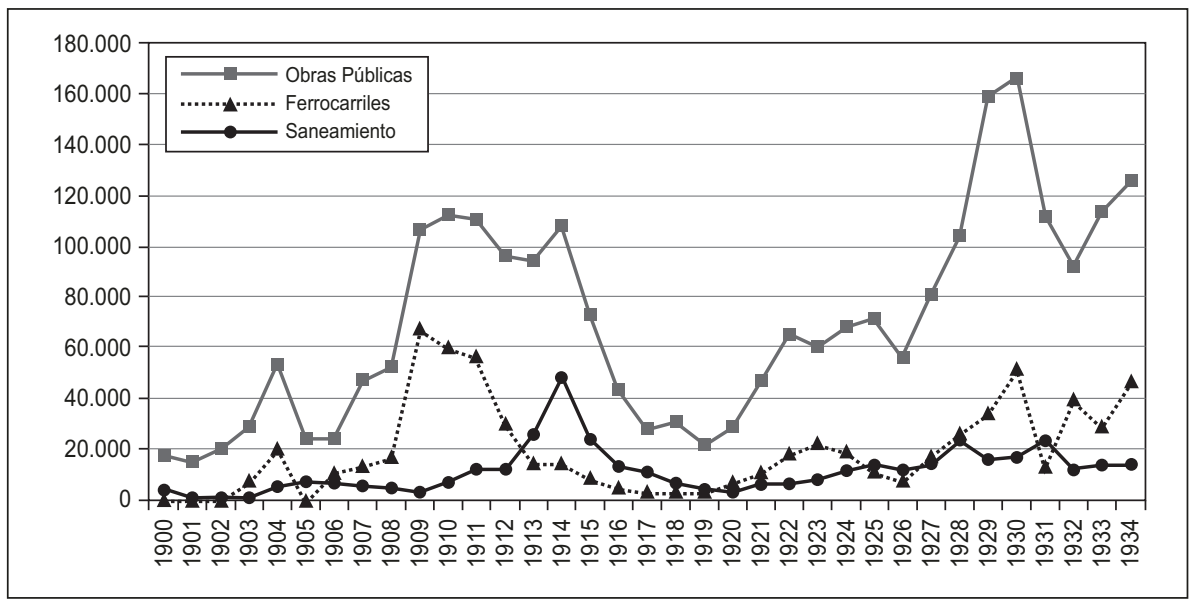

Fuente: Ver cuadro A4 del Apéndice. 
rrocamiento de Yrigoyen, y al mismo impacto de la crisis. Sobre esto volveremos en las dos últimas secciones.

Ahora bien, considerando el destino de esta inversión pública y en relación a los dos rubros que hemos seleccionado (ferrocarriles y saneamiento), podemos observar el papel central que jugaron en el comportamiento del conjunto. Su mayor participación se alcanzó precisamente en las fases de mayor crecimiento de la inversión total. Así, entre 1905 y 1914, ferrocarriles y saneamiento absorbieron más de un 50 por cien de lo destinado a toda la obra pública. Aún en la fase descendente del ciclo su participación se mantuvo en el orden del 40 por cien, nivel en torno al que osciló hasta 1934 (cuadro A4). Significativamente este nivel se sostuvo, y aún aumentó ligeramente, en 1930-1934.

En rigor es dable señalar el comportamiento disímil que tuvieron las inversiones en obras sanitarias y en ferrocarriles a partir de los años 1913-1914. Las primeras experimentaron en esos años un muy fuerte incremento asociado con el lanzamiento de un nuevo plan, que contribuyó a elevar el total de la obra pública, justo cuando los recortes en el gasto comenzaban a hacerse sentir. Por entonces las inversiones ferroviarias declinaban fuertemente. En los años veinte el alza de ambas series acompaña, con menor intensidad, el nuevo ascenso de la obra pública. Mientras las obras sanitarias registran sus picos máximos en 1928, y curiosamente, 1931, en el caso de Ferrocarriles, los guarismos más altos se verifican en los dos años de mayor aumento de la obra pública, 1929 y 1930, en cuyo desempeño contribuyen decisivamente. Si bien se aprecia un fuerte recorte en 1931 y 1932 (mitigado este ultimo año por la disposición de fondos para el pago de deudas previas), los montos asignados en 1933 y 1934 volvieron a los altos niveles previos, sólo superados por de los del año 1930. En cuanto a Obras Sanitarias, si bien sus registros no fueron tan importantes, presentó una mayor estabilidad en el nivel de las inversiones. En conjunto, el monto nominal asignado a estos dos rubros se había triplicado desde el piso de los años de la Primera Guerra, y superaba ligeramente, en estos últimos años, los valores de preguerra. En términos reales, luego de haberse reducido a poco más del 25 por cien del nivel de 1910-1914, se ubicaban en el último quinquenio muy cerca de aquel punto máximo.

De ambos rubros, la inversión ferroviaria fue mayoritaria. Entre 1906 y 1912 daba cuenta por sí sola de más del 40 por cien de la obra pública. Después su monto mermó considerablemente, al punto de ser superada por las inversiones en agua y saneamiento entre 1913 y 1919 . Entre 1920 y 1924 , y de 1930 a 1934, recuperó nuevamente su preeminencia, y superó en términos nominales, aun descontando los fondos asignados para pagos de deudas, los promedios de $1910-1914^{26}$.

26 Nuevamente, el nivel máximo de los gastos ferroviarios se alcanzó en 1930, con más de 68 millones de pesos, pero aún los montos de 1932-1934 estuvieron bien por encima de los de 1920 a 1928. 


\subsection{Inversiones reproductivas en un sector deficitario: los Ferrocarriles del Estado}

El desarrollo de las inversiones ferroviarias en este periodo formó parte del proceso de reconstrucción y ampliación de la red férrea estatal iniciada tras la crisis de $1890^{27}$. Para ese año, luego de la privatización de las antiguas líneas nacionales por parte de Juárez Celman, el Estado contaba con 320 kilómetros de vías, constituidas por unas líneas dispersas y otras en construcción de poco valor económico. A principios del siglo veinte, el gobierno inició un nuevo programa de construcciones, que continuaría más allá de la década del treinta, y llevaría la longitud total a más de 9.000 kilómetros en 1935.

La evolución del gasto público pone de manifiesto, en primer lugar, el carácter pro-cíclico de las inversiones, ya que las obras ferroviarias tuvieron lugar en las dos fases de auge, entre 1904 y 1914, y a partir de 1920. La primera fase de construcciones ferroviarias alcanzó su punto culminante entre

\section{CUADRO 1 \\ CAPITAL REALIZADO Y LONGITUD DE LOS FERROCARRILES DEL ESTADO, 1900-1935}

\begin{tabular}{|c|c|c|c|c|}
\hline Año & $\begin{array}{c}\text { Capital } \\
\text { realizado } \\
\text { Miles } \mathbf{\$} \mathbf{~ m} / \mathbf{n}\end{array}$ & Miles \$ oro & $\begin{array}{c}\text { Longitud } \\
\text { red } \\
\text { Km. }\end{array}$ & $\begin{array}{c}\text { Relac. } \\
\text { cap./km. } \\
\text { Miles \$ oro }\end{array}$ \\
\hline 1900 & 124.906 & 54.959 & 2.016 & 27,261 \\
\hline 1905 & 131.466 & 57.845 & 2.546 & 22,720 \\
\hline 1910 & 207.548 & 91.321 & 3.490 & 26,166 \\
\hline 1915 & 241.535 & $* 106.276$ & 4.793 & 22,173 \\
\hline 1921 & 389.398 & 171.335 & 6.310 & 27,153 \\
\hline 1925 & 604.022 & 265.770 & 6.878 & 38,643 \\
\hline 1930 & 762.475 & 335.489 & 8.979 & 37,362 \\
\hline 1935 & 847.159 & 372.750 & 9.188 & 40,569 \\
\hline $1900-1935$ & 722.253 & 317.791 & & \\
\hline
\end{tabular}

Fuente: Estadística de los Ferrocarriles en Explotación -EFCE- (1900-1935), y Administración General de Ferrocarriles del Estado -AGFE_, Memoria del año 1921.

* De acuerdo a EFCE, el capital realizado sería de 121.873 millones de pesos oro.

27 El periodo que tratamos en este artículo ha despertado un variado interés entre los especialistas. Uno de los temas clásicos ha sido el de las inversiones ferroviarias británicas antes de la Primera Guerra Mundial: Lewis (1983) y Zalduendo (1975). Goodwin (1974) y García Heras (1983) han investigado la relación de las empresas ferroviarias inglesas con los gobiernos radicales (19161930), en tanto Wright (1980) continuó el estudio hasta las nacionalizaciones del primer gobierno de Perón (1947-1948). Las inversiones francesas en este área han sido abordadas en Regalsky (2002, pp. 238-276 y 325-372). Los ferrocarriles estatales han sido estudiados por López (1994 y 2000) para el siglo XIX, y en relación con la formación de la AGFE por Palermo (2001) y Salerno (2003). 
1909 y 1912. Coincidió con una etapa de liquidez en el mercado internacional de capitales, que suministró los fondos necesarios. En los años veinte, las obras se iniciaron sin contar con los recursos y mediante el endeudamiento interno de corto plazo, previendo un futuro acceso al mercado internacional de capitales. Esto ocurrió recién a partir de 1924 con los nuevos empréstitos negociados en Estados Unidos, aunque sólo en 1927 pudieron cancelarse las operaciones de corto plazo antes mencionadas.

El programa de construcciones al que se volcaron estas inversiones comenzó a ser delineado hacia fines de la segunda presidencia de Roca. El plan de reconstrucción de la red estatal, impulsado desde el ministerio de Obras Públicas por Emilio Civit, apuntaba asimismo a fortalecer las alianzas políticas provinciales en vísperas de la sucesión presidencial. Se preveían obras en las provincias del Noroeste, Cuyo y el Litoral ${ }^{28}$, y la salida hacia los puertos de Santa Fe, Rosario y Bahía Blanca, además de la conexión ferroviaria con Bolivia.

Las administraciones siguientes mantuvieron la decisión de ampliar la red estatal, aunque difirieron en ciertos criterios y objetivos. Ramos Mexía, ministro de obras públicas de Figueroa Alcorta y de Sáenz Peña, mantuvo el proyecto de extensión de líneas hasta el puerto de Santa Fe pero suprimió los de Rosario y Bahía Blanca, con el fin expreso de evitar la competencia con las empresas privadas. Asimismo hizo sumar otras obras en la Mesopotamia y en los Territorios Nacionales ${ }^{29}$, así como nuevas conexiones con los países vecinos, Bolivia, Paraguay y Chile (cuadro 2$)^{30}$.

Las primeras obras se solventaron con recursos de la Tesorería General y con los dos empréstitos de obras públicas negociados en 1909 y 1911, cuyos montos sumaban 120 millones de pesos oro y se destinaron, en gran medida, a las construcciones ferroviarias ${ }^{31}$. La realización de este plan demandó varias décadas. La Primera Guerra Mundial impuso una pausa, y no fue hasta 1920 en que el gobierno radical de Yrigoyen retomó la construcción ferroviaria, aunque sin alcanzar los montos de la inversión de preguerra.

28 Las provincias del Noroeste eran Salta, Jujuy, Tucumán, Catamarca y La Rioja; las de Cuyo eran Mendoza, San Juan y San Luis, y las del Litoral, Santa Fe, Entre Ríos y Corrientes.

29 Los Territorios Nacionales eran las regiones que quedaron bajo el control directo del gobierno nacional a fines del siglo XIX, luego de las campañas militares contra los pueblos originarios, y que carecían de la autonomía política que preveía la Constitución para las Provincias. En algunos de estos Territorios se realizaron obras ferroviarias en la primera mitad del siglo xx para facilitar su comunicación con el resto del país y con el exterior: el Ferrocarril de Huaytiquina, en el Territorio de Los Andes, al oeste de la provincia de Salta, en dirección al puerto chileno de Antofagasta; el Ferrocarril de Viedma-San Antonio Oeste-Nahuel Huapi, por el Territorio de Río Negro, para su comunicación con Buenos Aires; la conexión Posadas-Encarnación (Paraguay), desde el Territorio de Misiones, a cargo de una empresa privada pero con subsidios estatales. En los Territorios de Chaco y Formosa (nordeste del país), como en algunos de los de la Patagonia (Río Negro, Chubut y Santa Cruz) se construyeron los Ferrocarriles de Fomento, uno de los cuales fue el ya mencionado de Viedma a Bariloche.

${ }^{30}$ Lacoste (2000, pp. 32-33), Palermo (2001) y Salerno (2003).

31 Pretto (1926, p. 28). 


\section{CUADRO 2}

OBRAS FERROVIARIAS AUTORIZADAS, 1902-1909

\begin{tabular}{|c|c|c|}
\hline Ley/Año & Obras aprobadas & Observaciones \\
\hline \multirow[t]{2}{*}{$\begin{array}{c}4064 / \\
1902\end{array}$} & $\begin{array}{l}\text { - Argentino del Norte: de Punta de los Llanos a San Juan } \\
\text { - Central Norte: de Jujuy a la frontera con Bolivia (Vía La Quiaca) } \\
\text { - Central Norte: de Perico a Ledesma }\end{array}$ & \\
\hline & - Estudios de las líneas de Ledesma a Orán, y de San Cristóbal a Santa Fe & \\
\hline $\begin{array}{r}4693 / \\
1905\end{array}$ & $\begin{array}{l}\text { Estudio de un Ferrocarril del Valle de Lerma a Huaytiquina u otro punto } \\
\text { próximo a la frontera chilena }\end{array}$ & $\begin{array}{l}\text { Iniciado en la primera presi- } \\
\text { dencia de Yrigoyen y termi- } \\
\text { nado en la de Perón }\end{array}$ \\
\hline \multirow[t]{7}{*}{$\begin{array}{c}4872 / \\
1905\end{array}$} & $\begin{array}{l}\text { Villa Mercedes (FCA) a Rosario } \\
\text { Córdoba a Río Cuarto (FCA) }\end{array}$ & $\begin{array}{l}\text { Suspendidas durante la ges- } \\
\text { tión de Ramos Mexía }\end{array}$ \\
\hline & Deán Funes (FCAN) a Rosario, con ramal a Villa María (FCA) & $\begin{array}{l}\text { Ley 6011: Deán Funes a } \\
\text { Laguna Paiva }\end{array}$ \\
\hline & Holmberg o sus inmediaciones hasta FCVilla Mercedes-Dolores (FCA) & \\
\hline & Barranqueras a Otumpa y Tintina, o Río Piedras o Metán (FCF) & $\begin{array}{l}\text { Ley 5559: de Barranqueras a } \\
\text { Metán }\end{array}$ \\
\hline & Formosa a Embarcación (FCF) & Reiterada por Ley 5559 \\
\hline & De Soto a Dolores (FCA) & \\
\hline & De San Juan a Jáchal & Proyecto anterior de 1886 \\
\hline \multirow[t]{3}{*}{$\begin{array}{c}5559 / \\
1908\end{array}$} & $\begin{array}{l}\text { De Puerto San Antonio (Territorio de Río Negro) hasta Nahuel Huapi } \\
\text { De Puerto Deseado hasta empalmar con la línea anterior, pasando por } \\
\text { Colonia San Martín, y con ramales a Comodoro Rivadavia, Lago Buenos } \\
\text { Aires y Colonia } 16 \text { de Octubre (Trevelín) }\end{array}$ & $\begin{array}{l}\text { Ramos Mexía suspendió la } \\
\text { conexión entre los ramales } \\
\text { patagónicos. Puerto Deseado a } \\
\text { Colonia Las Heras. Comodoro } \\
\text { Rivadavia a Cnia Sarmiento }\end{array}$ \\
\hline & $\begin{array}{l}\text { De Barranqueras hasta empalmar con el FCCN y ramal a la línea de } \\
\text { Añatuya al Chaco }\end{array}$ & $\begin{array}{l}\text { Aprobada anteriormente por } \\
\text { la Ley } 4872\end{array}$ \\
\hline & Formosa a Embarcación & \\
\hline \multirow{6}{*}{$\begin{array}{c}6011 / \\
1908\end{array}$} & Conexión con Bolivia & \\
\hline & Serrezuela a San Juan & \\
\hline & Chumbicha a La Rioja & \\
\hline & Andalgalá a Tinogasta & \\
\hline & Ledesma a Embarcación & \\
\hline & Cejas a Antilla & \\
\hline \multirow{6}{*}{$\begin{array}{c}6016 / \\
1908\end{array}$} & Puerto Diamante a Estación Crespo del FC de Entre Ríos & \multirow{2}{*}{$\begin{array}{l}\text { Construido por The Railway } \\
\text { Company Lted. y la Cía. del } \\
\text { Ferrocarril del Nordeste } \\
\text { Argentino }\end{array}$} \\
\hline & $\begin{array}{l}\text { De estación Hasenkamp, del mismo Ferrocarril, pasando por Federal, } \\
\text { hasta Curuzú Cuatiá del Ferrocarril Nordeste Argentino }\end{array}$ & \\
\hline & De la línea troncal a San José Feliciano & \multirow{4}{*}{$\begin{array}{l}\text { Construido por Administra- } \\
\text { ción y por intermedio de con- } \\
\text { tratistas privados }\end{array}$} \\
\hline & De Feliciano a La Paz & \\
\hline & De Feliciano al Sauce (Corrientes) & \\
\hline & De Curuzú Cuatiá al Sauce y Esquina & \\
\hline \multirow[t]{4}{*}{$\begin{array}{c}6341 / \\
1909\end{array}$} & $\begin{array}{l}\text { De Puerto Diamante hasta un punto de la línea de Monte Caseros a } \\
\text { Posadas }\end{array}$ & \multirow[t]{4}{*}{$\begin{array}{l}\text { Construido por Administra- } \\
\text { ción }\end{array}$} \\
\hline & $\begin{array}{l}\text { Desde Paraná empalmando con la anterior cerca de estación María } \\
\text { Grande }\end{array}$ & \\
\hline & Otros ramales para empalmar con líneas de Entre Ríos y Corrientes & \\
\hline & $\begin{array}{l}\text { Autorización a adquirir el ramal de Crespo a Hasenkamp, de la Cía. del } \\
\text { FC de Entre Ríos }\end{array}$ & \\
\hline
\end{tabular}

Fuente: Memorias del Ministerio de Obras Públicas (1904, pp. 25-26) y (1905, pp. 15-39), Pretto (1926, pp. 19-99), y Anales de Legislación Argentina. Años 1889-1919 (1954, p. 655). 


\section{CUADRO 3}

GASTO PÚBLICO DESTINADO A LOS FERROCARRILES DEL ESTADO

(en miles de pesos moneda nacional)

\begin{tabular}{|c|c|c|c|c|}
\hline Periodo & $\begin{array}{c}\text { Obras y } \\
\text { estudios }\end{array}$ & $\begin{array}{c}\text { Mejoras } \\
\text { y equipos }\end{array}$ & \multicolumn{1}{|c|}{ Total } & $\begin{array}{c}\text { Total } \\
\text { general }\end{array}$ \\
\hline $1900-1904$ & 18.690 & 655 & 19.345 & 19.376 \\
\hline $1905-1909$ & 88.397 & 8.903 & 97.300 & 97.987 \\
\hline $1910-1914$ & 139.356 & 23.552 & 162.908 & 167.177 \\
\hline $1915-1919$ & 11.242 & 14.630 & 25.872 & 26.222 \\
\hline $1920-1924$ & 85.847 & 27.137 & 112.984 & 113.517 \\
\hline $1925-1929$ & 87.908 & 36.842 & 124.750 & 124.750 \\
\hline $1930-1934$ & 100.314 & 65.309 & 165.623 & 204.524 \\
\hline
\end{tabular}

Fuente: MCGN (1900-1934), passim.

Nota: Entre 1930-1934 hubo 55.491 millones de pesos destinados a pagos de intereses, déficit de explotación y deudas diversas.

En la década del veinte la mayor parte de las inversiones se destinó a la continuación y conclusión de las obras en construcción desde antes de 1914, y de otras anheladas desde larga data, y que contaban con estudios previos, como la conexión de Salta con Chile (Ferrocarril de Huaytiquina) y el segundo enlace ferroviario con Bolivia por Yacuiba. Como puede observarse en el cuadro 4, las obras que demandaron más inversiones en forma individual fueron las conexiones ferroviarias con los países vecinos, aunque tomadas en su conjunto las obras en las provincias, y luego las de los territorios nacionales, fueron mayoritarias. Entre 1930 y 1934 se registró otro pico de inversiones, ahora superior al de 1910-1914, y volcado en proporción no desdeñable a mejoras y equipamiento ${ }^{32}$.

El desarrollo de estas inversiones no estuvo exento de avatares. En una primera fase, hasta 1910, el marco fue de escasa autonomía por parte de las administraciones ferroviarias, que lograron generar un superávit en la explotación y una aceptable transparencia en la contabilidad de los fondos. Los fondos para las inversiones y para la explotación eran entregados por la Tesorería General, ante la cual debía depositarse el total de lo recaudado ${ }^{33}$. Las principales discusiones giraban por entonces en torno a la cuestión de las rutas de acceso al litoral y a la magnitud de las inversiones a canalizar hacia los territorios nacionales.

\footnotetext{
32 En rigor los picos de inversión fueron de 1929 a 1930, y de 1933 en adelante.

33 En 1900 el Congreso autorizó a los administradores a invertir el excedente del producto de explotación en las mismas líneas. Para ello se conservó el procedimiento anterior, que permitía conocer el movimiento de ingresos y salidas de los fondos.
} 
CUADRO 4

DISTRIBUCIÓN DE LAS OBRAS FERROVIARIAS, 1900-1929

\begin{tabular}{|c|c|c|c|c|c|c|}
\hline Año & $1900-1907$ & $1908-1915$ & 1916-1919 & $1920-1924$ & 1925-1929 & $1900-1929$ \\
\hline Rubros & \multicolumn{6}{|c|}{ En miles de pesos $\mathrm{m} / \mathrm{n}$} \\
\hline Varios (1) & & 13.745 & & & 22.873 & 36.618 \\
\hline FF.CC en las provincias (2) & 11.074 & 111.449 & 3.096 & 27.144 & 26.125 & 178.889 \\
\hline FF.CC de Fomento (3) & & 73.452 & 3.563 & 18.414 & 15.549 & 110.980 \\
\hline FF.CC a Bolivia (4) & 24.588 & & 100 & 4.333 & 9.715 & 38.737 \\
\hline FC a Chile (Huaytiquina) (5) & 573 & & & 29.405 & 5.600 & 35.578 \\
\hline FF.CC Mesopotámicos (6) & 729 & 18.928 & & 6.550 & 8.045 & 34.253 \\
\hline
\end{tabular}

Fuente: $M H$ (1900-1911) y MCGN (1912-1928).

Notas: (1) En 1908-1914, Ferrocarril de Córdoba al Noroeste, y en 1925-1929, obras sin discriminar. (2) Santa Fe, Córdoba, San Luis, Mendoza, San Juan, La Rioja, Catamarca, Santiago del Estero, Tucumán, Salta y Jujuy, excepto las obras de conexión con Bolivia hasta 1925, más gastos del Cablecarril a Famatina y pagos al Ferrocarril Sud por la línea a Neuquén. Se incluyen los estudios. (3) Obras ferroviarias previstas por la Ley 5559 en los Territorios de la Patagonia y del Chaco. (4) Incluye la conexión por La Quiaca y la de Embarcación a Yacuiba. (5) Futura línea de Salta a la frontera con Chile. (6) Incluyen los fondos provistos para la conexión de las líneas privadas con las de Paraguay.

En 1910, al ponerse todas las líneas bajo la órbita de un organismo central, la Administración General de los Ferrocarriles del Estado (AGFE), los registros perdieron visibilidad. En principio, la AGFE contaba con sus propios recursos para la atención de sus gastos corrientes, en tanto las obras se atendían con fondos de la Tesorería ${ }^{34}$. Sin embargo, como a partir de 1912 debió sobrellevar un déficit creciente ${ }^{35}$, dependió de hecho de los aportes de la Tesorería no sólo para las nuevas obras sino también para asegurar su propio funcionamiento. En esta segunda fase, y sobre todo a partir de 1916, los principales debates estuvieron centrados en la falta de información adecuada sobre los ingresos y gastos, y la recurrente necesidad de elevadas sumas que la Administración requería para cubrir su déficit. Estos asuntos, lo mismo que la escasa diferenciación de los fondos destinados a la inversión y a la explotación, fueron objeto de crítica en la prensa y en el Congreso.

A su turno, las tensiones entre el Poder Ejecutivo y el Congreso provocaron retrasos en la asignación de fondos, que contribuyeron a generar una deuda flotante específica de los Ferrocarriles del Estado, cuyo monto

34 Entre 1910 y 1917 existieron todavía registros contables que permiten conocer el movimiento de la explotación. A partir de 1918 la información se encuentra solamente en las estadísticas de la Dirección General de Ferrocarriles. De la confrontación de estos datos con los de las Memorias de la Contaduría General de la Nación surgen algunas diferencias que hemos considerado irrelevantes para el análisis aquí propuesto.

35 Producto de la habilitación de líneas y ramales en zonas cada vez menos rentables, así como de la venta, en 1909, de la línea con cuyos beneficios se solventaba el déficit del resto, el Ferrocarril Andino. 
preciso se desconocía. A fines de 1924, y en el marco de una intervención contable por parte del Poder Ejecutivo, se pudo determinar que esa deuda ascendía a más de 180 millones de pesos moneda nacional, y sus servicios trepaban a los diez millones de pesos anuales. Recién en 1927, mediante la emisión de un empréstito interno y externo, se pudo consolidar esta deuda, y por la misma ley presupuestaria se convalidaron también las obras ya realizadas ${ }^{36}$.

Todavía continuaron generándose problemas con el uso de los fondos después de la intervención contable de 1924, que provocaron una serie de medidas administrativas que volvieron a cercenar la autonomía de la AGFE. De hecho, en los últimos cuatro años de la presidencia de Alvear (1924-1928), las obras quedaron reducidas a un mínimo, para ser reactivadas en los años de la presidencia de Yrigoyen (1929-1930) y, luego de su derrocamiento, durante la gestión del general Justo ${ }^{37}$.

Estos avatares se reflejaron en los numerosos cambios en la conducción del organismo: Iturbe, Ramallo, Fernández Beschtedt y Enrique Pérez fueron los administradores titulares hasta 1930, complementados por otros interinos en los diversos periodos de acefalía. Los ingenieros que ocupaban las principales posiciones técnicas tuvieron una mayor estabilidad, asumiendo en varios casos la conducción interina.

\section{LAS INVERSIONES PÚBLICAS EN OBRAS DE PROVISIÓN DE AGUA Y SANEAMIENTO URBANO: UN CASO DE REPRODUCTIVIDAD SOCIAL Y SUPERÁVIT FINANCIERO}

Las primeras inversiones en obras de provisión de agua y saneamiento en la Argentina tuvieron lugar en la ciudad de Buenos Aires, casi al mismo tiempo que cundían las epidemias del cólera y la fiebre amarilla, a comienzos del último tercio del siglo XIX. A partir de 1868 y a lo largo de la década de 1870 se fueron habilitando las primeras instalaciones, a cargo por entonces del estado provincial, y que comprendían un establecimiento potabilizador en Recoleta, y los primeros 90 kilómetros de cañerías para el su-

36 Otra controversia giraba sobre los criterios para clasificar algunos de los gastos como atinentes a la explotación o la inversión. Por otra parte los gastos se rendían a la Contaduría General con mucha demora. Aunque los comprobantes se recibían hasta el mes de marzo del año siguiente, quedaban muchos gastos sin registrarse hasta el ejercicio siguiente.

${ }^{37}$ El presidente radical Hipólito Yrigoyen asumió su segundo mandato en octubre de 1928 y en septiembre de 1930 fue derrocado por un golpe militar que llevó a la presidencia al general José Félix Uriburu. Éste fue sucedido en 1932 por el general Agustín P. Justo, al frente de una coalición de conservadores y socialistas y radicales disidentes, tras unas elecciones muy cuestionadas en las que el partido radical se abstuvo. Justo designó a Pablo Nogués como Administrador General de la AGFE, cargo en el que permaneció hasta su muerte (1932-1943); Nogués había sido titular de la Dirección General de Ferrocarriles entre 1911 y 1918, y de Obras Sanitarias de la Nación entre 1925 y 1928. 
ministro de agua. Una etapa de gran actividad se registró en la década de 1880 , cuando las obras pasaron a cargo del gobierno nacional a raíz de la federalización de la ciudad capital (véase el cuadro 5). Se construyeron entonces el gran depósito distribuidor de la calle Córdoba, la red de desagües cloacales y la primera "cloaca máxima», con su correspondiente sifón por debajo del Riachuelo. Estas obras, terminadas a comienzos de los años 1890 tras un fallido intento de privatización a favor de una compañía inglesa (la Buenos Aires Water Supply and Drainage Company), completaban el plan diseñado en 1871 por el ingeniero Bateman para el primitivo casco urbano de Buenos Aires ${ }^{38}$.

Sin embargo, la mayor expansión del gasto público en este área se registró después de 1900, y estuvo orientada en dos direcciones: la realización de un nuevo plan de obras en Buenos Aires - que llevó la extensión de la red de cañerías de 1,6 a 4,7 millones de metros lineales, según puede verse en el cuadro 6- y la extensión de los servicios esenciales a un gran número de ciudades y pueblos del interior del país.

En sus primeros años de actividad, la Comisión de Obras de Salubridad de la Capital, que retomó a su cargo la construcción y explotación de las obras a partir de 1891, se ocupó de completar las obras en la ciudad de Buenos Aires entregadas por los concesionarios, y añadir algunos nuevos

\section{CUADRO 5}

LONGITUD DE CAÑERÍAS DE AGUA Y CLOACAS EN BUENOS AIRES (en metros lineales)

\begin{tabular}{|c|c|c|}
\hline Año & Agua & Cloacas \\
\hline 1874 & 90.115 & \\
\hline 1882 & 97.673 & \\
\hline 1886 & 387.075 & \\
\hline 1889 & 436.448 & 216.048 \\
\hline 1894 & 604.822 & 342.852 \\
\hline 1902 & 927.960 & 376.592 \\
\hline 1909 & 1.110 .285 & 516.695 \\
\hline 1914 & 2.234 .418 & 752.393 \\
\hline 1917 & 3.058 .212 & 1.626 .000 \\
\hline 1929 & 3.979 .417 & 2.527 .111 \\
\hline
\end{tabular}

Fuente: OSN (1931, p. 638).

${ }^{38}$ Sobre el desarrollo de las obras en los siglos XIX y xx pueden consultarse Bordi de Ragucci (1997), Radovanic, Tartarini y cols. (1999), Rey (2003), Silvestri (2004) y Tartarini (2007). Véanse también los clásicos Baca (1918) y Candioti (1918). Una buena reseña de las décadas precedentes en DGOSN (1902, pp. 24-31). Sobre otro caso, el de Rosario, véase Lanciotti (2007). 
distritos. Entre ellos, los de Belgrano y Flores (recientemente incorporados al municipio) que, a diferencia del radio céntrico, fueron abastecidos desde pozos semisurgentes.

En 1898 la repartición fue transformada en Dirección General de Obras de Salubridad de la Nación (DGOSN), e integrada en el Ministerio de Obras Públicas. Al poco tiempo los gobiernos de numerosas provincias comenzaron a solicitar apoyo para la construcción de obras de provisión de agua en sus respectivas ciudades capitales. Un decreto de 1899 dispuso que esas obras debían ser aprobadas previamente por el Congreso, y construidas y operadas por la DGOSN. Restaba el problema del financiamiento que, por el régimen federal existente, debía incumbir a los respectivos gobiernos locales, faltos sin embargo de la solvencia necesaria. En 1900 la Ley 3967 afectó a ese destino el 50 por cien de las sumas que, para obras filantrópicas, correspondían a cada provincia de lo recaudado por la Lotería Nacional. Finalmente, la Ley 4158 de 1903, dispuso la emisión de bonos por parte del gobierno nacional, cuyo servicio se atendería con el producto de la explotación de las obras, previa celebración de convenios con las provincias que se acogieran a este régimen ${ }^{39}$. Casi todos los gobiernos se acogieron a la ley (Tucumán, Catamarca, La Rioja, Santiago del Estero, Salta, Jujuy, Mendoza, Corrientes, Entre Ríos, Santa Fe, Córdoba, San Luis y San Juan). Hacia fines de 1912 el gobierno nacional llevaba gastado en todas estas obras unos 33 millones de pesos ${ }^{40}$.

Hacia 1905 se habían dado por finalizadas las últimas obras complementarias en los barrios del radio antiguo de la Capital (el llamado «radio Bateman»). Se hacía necesario un plan que contemplara los requerimientos del resto de la ciudad, en lo que sería denominado el «Radio Nuevo», y que comprendía una superficie de 16.000 hectáreas, frente a las 3.000 del anterior. El nuevo plan, terminado de redactar en 1908 y autorizado por la Ley 6385 de 1909, contemplaba entre las obras más significativas la ampliación del establecimiento Recoleta, la construcción de una segunda, y mucho más grande, planta potabilizadora en Palermo (con su respectiva toma de agua en el Río de la Plata), dos nuevos depósitos distribuidores en los barrios de Caballito y Devoto, una vasta red de cañerías de suministro de agua y otra más costosa de colectoras cloacales. El sistema se coronaría con la construcción de una Segunda Cloaca Máxima, de 45 kilómetros de extensión, entre el norte de la Capital y la localidad de Berazategui, por donde desembocaría en el Río de la Plata, así como de un segundo sifón para su cruce del Riachuelo. Las obras, pensadas para abastecer en lo inmediato a una población de algo más de un millón de habitantes, debían ser capaces de aten-

${ }^{39}$ La Ley 3967 y sus antecedentes, en DSCD (1900, p. 484). La Ley 4158, en DGOSN (1903, pp. 166-176).

${ }_{40}$ Sobre este proceso véase Regalsky (2007, pp. 5-19). El gobierno de la provincia de Buenos Aires fue el único en no adherirse a la Ley 4158 para las obras en su ciudad capital, La Plata, de las que se hizo cargo directamente. Véase BOP (1935, pp. 253-266). 
der, a través de sucesivas ampliaciones, una población máxima de seis millones de habitantes con un consumo potencial diario de tres millones de metros cúbicos ${ }^{41}$.

Las obras tomaron impulso recién a fines de 1912, una vez que el Congreso convalidó, por la Ley 8889, la transformación de la DGOS en Obras Sanitarias de la Nación, un nuevo organismo con características autárquicas similares a la AGFE. La financiación de las obras, que debían ascender a los 168 millones de pesos, se convirtió en la cuestión de más difícil resolución. Las reticencias del Congreso a permitir la contratación de empréstitos externos por el flamante organismo recién se lograron vencer hacia fines de 1913, lo que obligó a recurrir hasta entonces a fuertes adelantos de la Tesorería $^{42}$. Las buenas noticias parlamentarias llevaron a acelerar la marcha de las obras, al tiempo que el gobierno negociaba en Gran Bretaña dos fuertes adelantos a cuenta de un empréstito de monto aún mayor ${ }^{43}$.

Así, el monto invertido en 1913 (casi 23 millones de pesos) se duplicó en 1914 (más de 46 millones) y al finalizar 1915 acumulaba un total de más de 110 millones. A modo de referencia, las obras completas del radio antiguo se habían valuado en 115 millones. Asimismo los importantes excedentes líquidos obtenidos de la explotación de las obras hasta 1915 permitieron reforzar los fondos disponibles ${ }^{44}$. Sin embargo, el estallido de la guerra había cambiado algunos parámetros fundamentales. El gran empréstito que se negociaba a comienzos de 1914 nunca se pudo concretar y esto obligó a reajustar el ritmo de los trabajos ya acordados. Consecuentemente la marcha de las obras se fue desacelerando, y esto no sólo por el agotamiento de los fondos. El otro gran problema fue el de las demoras en el arribo de los materiales, y la rescisión de numerosos contratos que no pudieron ser cumplidos bajo las nuevas condiciones bélicas, agravadas a partir de 1916 por la guerra submarina. No obstante todas estas dificultades, las obras fundamentales se fueron habilitando en esos años: las primeras instalaciones de la nueva planta potabilizadora, el depósito distribuidor de Caballito, y la conexión al nuevo sistema de Belgrano y Flores. Los desagües cloacales tenían un retraso más considerable, pero ya se había completado el tramo urbano de la Segunda Cloaca Máxima ${ }^{45}$.

${ }^{41}$ De hecho, en lo esencial, son las que continúan abasteciendo a la actual población de Buenos Aires y su anillo conurbano.

${ }^{42}$ Un buen relato de estos avatares en OSN (1919, pp. 133-135).

${ }^{43}$ Los adelantos, otorgados inicialmente por Midland Bank y Baring Brothers por un total de ocho millones de libras (unos 90 millones de pesos), debían servir de preámbulo a un empréstito por el doble de esa suma. Como se indicó en la nota 19, fueron consolidados en 1915 en sendos créditos a cinco años a cargo de Baring (cinco millones de libras) y Morgan y City Bank (25 millones de dólares). Peters (1934, pp. 79-82).

${ }^{44}$ En 1914 y en 1915 el superávit de la explotación superó los diez millones de pesos anuales, en tanto que la suma que OSN tenía que entregar para el servicio del empréstito por el que se había rescindido la concesión en 1891 , era de 4.368 .000 pesos.

${ }^{45} \operatorname{OSN}(1916$, pp. 99-103). 
La trayectoria de la inversión anual, luego del pico de 1913-1915, fue bajando hasta un mínimo de seis millones de pesos en 1920 (cuadro 6). Para entonces los fondos previstos originalmente para el plan completo se habían agotado y aún quedaban obras pendientes. Más aún, el aumento de la población y el consumo de agua en la Capital hacía necesario ampliar las instalaciones de tratamiento y conducción del agua extraída del río. En ese sentido, la introducción de filtros rápidos en lugar de los clásicos filtros lentos ingleses, así como la electrificación de un sistema originalmente alimentado por bombas de vapor, fueron algunos de los nuevos elementos contemplados ${ }^{46}$.

En los años siguientes se fueron completando las restantes obras: el depósito de Villa Devoto, que permitía abastecer a los barrios más alejados, los tramos finales de la Segunda Cloaca Máxima, y la habilitación en Palermo de los primeros filtros rápidos. El tendido de cañerías hacia los barrios más alejados pudo comenzar a encararse a partir del contrato con la firma francesa Pont-a-Mousson, en octubre de 1920, que después de varios años de dilaciones - por el contexto bélico- permitió efectivizar la compra de 200 kilómetros (unas 20.000 toneladas) de cañerías maestras y distribuidoras ${ }^{47}$.

Mientras tanto, la inversión en las provincias había ido disminuyendo de año en año, luego de 1912, hasta alcanzar un mínimo de 360.000 pesos en 1919. El creciente requerimiento de los gobiernos provinciales llevó ese año a sancionar la Ley 10.998, por la cual se autorizó el estudio, proyecto y construcción de las obras de provisión de agua en todas las ciudades que tuvieran más de 3.000 habitantes, y desagües cloacales en aquellas que tuvieran más de 8.000. De todos modos, habría que esperar a 1924, una vez colocadas las primeras emisiones de títulos internos destinadas a su financiamiento, para que las obras tomaran impulso. Las inversiones se mantuvieron por ocho años en una media anual de nueve millones de pesos, alcanzando su máximo nada menos que en 1931, un año caracterizado por la baja general de la obra pública.

En cuanto a las obras en la Capital, hacia 1925 estaban concluyendo los últimos trabajos relacionados con el plan de 1908, y se llevaban gastados unos 200 millones de pesos. En 1924 el gobierno nacional presentó en el Congreso el segundo plan maestro, que quedó sin ser tratado por las Cámaras. En su reemplazo se implementaron sucesivos planes parciales aprobados junto al presupuesto nacional. Uno de los primeros trabajos fue la construcción de las nuevas baterías de filtros rápidos en el establecimiento Palermo, con capacidad para producir un millón de metros cúbicos diarios de agua potabilizada, a fin de radiar definitivamente al viejo establecimiento Recoleta. Las obras se habilitaron apresuradamente en septiembre de 1928,

\footnotetext{
$46 \operatorname{OSN}$ (1919, pp. 136-141).

47 OSN (1920, pp. 8-9 y 177-178).
} 


\section{CUADRO 6}

INVERSIONES ANUALES EN OBRAS SANITARIAS, 1911-1934

(en miles pesos moneda nacional)

\begin{tabular}{|c|c|c|c|c|c|}
\hline Años & Capital & $(\%)$ & $\begin{array}{c}\text { Provincias } \\
\text { y territorios }\end{array}$ & $(\%)$ & $\begin{array}{c}\text { Total } \\
\text { general }\end{array}$ \\
\hline $\begin{array}{l}1900 \\
1901 \\
1902 \\
1903 \\
1904\end{array}$ & $\begin{array}{r}2.711,3 \\
693,0 \\
436,0 \\
317,7 \\
1.762,5\end{array}$ & & $\begin{array}{r}0,0 \\
63,8 \\
370,6 \\
493,1 \\
2.071,6\end{array}$ & & $\begin{array}{r}2.711,3 \\
756,8 \\
806,6 \\
810,8 \\
3.834,1\end{array}$ \\
\hline 1900-1904 & $1.184,1$ & 66,4 & 599,8 & 33,6 & $1.783,9$ \\
\hline $\begin{array}{l}1905 \\
1906 \\
1907 \\
1908 \\
1909 \\
\end{array}$ & $\begin{array}{r}2.582,3 \\
1.844,1 \\
1.165,9 \\
200,0 \\
758,2 \\
\end{array}$ & & $\begin{array}{l}3.207,8 \\
4.225,7 \\
4.225,7 \\
4.225,7 \\
2.035,8\end{array}$ & & $\begin{array}{l}5.790,1 \\
6.069,8 \\
5.391,6 \\
4.425,7 \\
2.794,0\end{array}$ \\
\hline 1905-1909 & $1.310,1$ & 26,8 & $3.584,1$ & 73,2 & $4.894,2$ \\
\hline $\begin{array}{l}1910 \\
1911 \\
1912 \\
1913 \\
1914 \\
\end{array}$ & $\begin{array}{r}1.900,0 \\
7.626,6 \\
8.329,5 \\
22.868,4 \\
46.857,3 \\
\end{array}$ & & $\begin{array}{l}4.483,8 \\
3.650,0 \\
3.893,2 \\
2.900,0 \\
1.995,7 \\
\end{array}$ & & $\begin{array}{r}6.383,8 \\
11.276,6 \\
12.222,7 \\
25.768,4 \\
48.853,0 \\
\end{array}$ \\
\hline 1910-1914 & $17.516,4$ & 83,8 & $3.384,5$ & 16,2 & $20.900,9$ \\
\hline $\begin{array}{l}1915 \\
1916 \\
1917 \\
1918 \\
1919\end{array}$ & $\begin{array}{r}25.046,3 \\
14.361,6 \\
14.862,2 \\
10.681,4 \\
6.727,5\end{array}$ & & $\begin{array}{r}1.138,6 \\
1.116,4 \\
591,9 \\
579,5 \\
366,3\end{array}$ & & $\begin{array}{r}26.185,0 \\
15.478,0 \\
15.454,1 \\
11.260,8 \\
7.093,7\end{array}$ \\
\hline 1915-1919 & $14.335,8$ & 95,0 & 758,5 & 5,0 & $15.094,3$ \\
\hline $\begin{array}{l}1920 \\
1921 \\
1922 \\
1923 \\
1924 \\
\end{array}$ & $\begin{array}{r}6.250,0 \\
10.018,2 \\
5.786,6 \\
7.630,5 \\
8.781,2 \\
\end{array}$ & & $\begin{array}{l}1.271,9 \\
1.351,2 \\
3.470,9 \\
3.772,9 \\
8.565,1 \\
\end{array}$ & & $\begin{array}{r}7.522,0 \\
11.369,4 \\
9.256,5 \\
11.403,4 \\
17.346,3 \\
\end{array}$ \\
\hline 1920-1924 & $7.693,3$ & 67,6 & $3.686,4$ & 32,4 & $11.379,5$ \\
\hline $\begin{array}{l}1925 \\
1926 \\
1927 \\
1928 \\
1929 \\
\end{array}$ & $\begin{array}{r}8.052,6 \\
9.041,8 \\
13.574,7 \\
24.080,4 \\
14.514,6 \\
\end{array}$ & & $\begin{array}{r}11.497,4 \\
7.715,2 \\
7.516,8 \\
8.278,7 \\
7.381,4 \\
\end{array}$ & & $\begin{array}{l}19.550,0 \\
16.757,0 \\
21.091,5 \\
32.359,1 \\
21.896,0 \\
\end{array}$ \\
\hline 1925-1929 & $13.852,8$ & 62,0 & $8.477,9$ & 38,0 & $22.330,7$ \\
\hline $\begin{array}{l}1930 \\
1931 \\
1932 \\
1933 \\
1934 \\
\end{array}$ & $\begin{array}{r}12.839,3 \\
12.712,9 \\
7.965,3 \\
9.469,5 \\
10.089,6\end{array}$ & & $\begin{array}{r}10.658,8 \\
14.355,0 \\
4.879,2 \\
7.277,2 \\
5.624,8\end{array}$ & & $\begin{array}{l}23.498,1 \\
27.067,9 \\
12.844,5 \\
16.746,7 \\
15.714,4\end{array}$ \\
\hline 1930-1934 & $10.615,3$ & 55,4 & $8.559,0$ & 44,6 & $19.174,3$ \\
\hline 1900-1934 & $9.501,1$ & 69,6 & $4.150,0$ & 30,4 & $13.651,1$ \\
\hline
\end{tabular}

Fuente: DGOSN (1900-1911, passim) y OSN (1912-1934, passim). 
justo antes de finalizar su mandato el presidente Alvear, y ese año las inversiones en Capital alcanzaron los 24 millones de pesos, el monto más alto después de 1914-1915. Al iniciarse la década de 1930 las actividades se concentraban en la construcción del sistema de desagües pluviales y en los preparativos para tender la Tercera Cloaca Máxima, que se juzgaba indispensable para el desarrollo de la red, dado el crecimiento de las localidades vecinas a la capital. Las nuevas inversiones acumulaban más de 100 millones de pesos desde 1927.

Un aspecto relevante en el desarrollo de estas obras fue el de la marcha de la explotación. En contraste con los Ferrocarriles del Estado, los resultados fueron altamente superavitarios, sobre todo dentro del radio capitalino. En 1910 se destacaba con orgullo el bajo coeficiente de gastos, del 33,81 por cien, «proporción que no alcanza ninguna de las empresas de ferrocarriles -ni otras análogas- en nuestro país y muy pocas en el extranjero» ${ }^{48}$. Con todo, recién en 1908 el producto neto había alcanzado la suma necesaria para atender el servicio de intereses y amortización del empréstito de 1892, con el que se había re-estatizado el servicio. La progresión del producto neto siguió hasta 1914 y 1915, en que alcanzó los diez millones de pesos.

A partir de 1916 y más acentuadamente desde 1918, los gastos comenzaron a subir más que los ingresos, y el producto neto quedó durante diez años por debajo de los valores de 1914-1915. El coeficiente de gastos se ubicó por encima del 60 por cien. Entre los rubros más significativos se mencionaban las alzas salariales, así como en el precio de los combustibles y de ciertos insumos para la potabilización, que serían objeto de una sustitución por producción propia en los siguientes años ${ }^{49}$. Recién hacia 1924-1925 los gastos se pudieron contener, simultáneamente con una aceleración en el crecimiento de los ingresos, debido a la multiplicación de las conexiones domiciliarias que la terminación de las obras hacía posible. De este modo, el coeficiente de explotación volvió a bajar hasta cerca del 40 por cien. Significativamente, la trayectoria ascendente se mantuvo incluso en los años de la crisis, de manera que el producto neto de 19251929 totalizó un 150 por cien por arriba del de 1910-1914, y el de 19301934, un 200 por cien.

Por entonces los gastos financieros que debían atenderse con esos recursos habían subido enormemente. De los 4,6 millones que insumía el ser-

${ }^{48} \operatorname{DGOSN}(1909$, p. 93). Esta secuencia ascendente puede ayudar a explicar la estabilidad de los cuadros directivos, tanto a nivel de la dirección técnica - que estuvo manejada en casi todo el periodo por dos figuras: los ingenieros González (1898-1911) y Paitoví (1914-1931) — como de la conducción general del organismo, en la que se destacaron los ingenieros Villanueva (1900-1911), González (1912-1914), Candioti (1914-1925) y Paitoví (1931-1934). En el caso de González y Paitoví, culminaron así una trayectoria previa en la conducción técnica. Tartarini (2007, pp. 52-54), AySA (s/f), DGOSN (1900-1911) y OSN (1912-1934, passim).

${ }_{49}$ En 1917 se habilitó una fábrica propia de sulfato de aluminio, y en 1923 otra de ácido sulfúrico, que fueron pioneras en el desarrollo industrial del área y posibilitaron una importante reducción de costos. Rey (2003, pp. 68-72). 


\section{CUADRO 7}

OBRAS SANITARIAS DE LA NACIÓN. RESULTADOS DE LA EXPLOTACIÓN (en miles de pesos moneda nacional) promedios anuales

\begin{tabular}{|l|c|c|c|c|c|c|c|c|c|c|c|}
\hline \multirow{5}{*}{ Años } & \multicolumn{5}{|c|}{ Capital } & \multicolumn{3}{c|}{ Provincias } & \multicolumn{3}{c|}{$\begin{array}{c}\text { Relación } \\
\text { cap./pcias. }\end{array}$} \\
\cline { 2 - 12 } & $\begin{array}{c}\text { Ingresos } \\
\text { totales }\end{array}$ & Gastos & $\begin{array}{c}\text { Coef. } \\
\text { explot. }\end{array}$ & $\begin{array}{c}\text { Prod. } \\
\text { neto }\end{array}$ & $\begin{array}{c}\text { Serv. } \\
\text { deuda }\end{array}$ & Ingresos & Gastos & $\begin{array}{c}\text { Coef. } \\
\text { explot. }\end{array}$ & $\begin{array}{c}\text { Prod. } \\
\text { neto }\end{array}$ & Ingresos & $\begin{array}{c}\text { Prod. } \\
\text { neto }\end{array}$ \\
\hline $\begin{array}{l}1900- \\
1904\end{array}$ & 5.451 & 1.945 & 35,7 & 3.506 & 4.424 & & & & & & \\
\hline $\begin{array}{l}1905- \\
1909\end{array}$ & 7.184 & 2.542 & 35,4 & 4.642 & 4.683 & & & & & & \\
\hline $\begin{array}{l}1910- \\
1914\end{array}$ & 12.195 & 3.776 & 31,0 & 8.426 & 4.683 & 1.887 & 1.456 & 77,1 & 431 & 6,5 & 19,5 \\
\hline $\begin{array}{l}1915- \\
1919\end{array}$ & 16.294 & 8.302 & 50,9 & 7.992 & 4.683 & 2.420 & 2.551 & 105,4 & -131 & 6,7 & \\
\hline $\begin{array}{l}1920- \\
1924\end{array}$ & 21.921 & 13.624 & 62,2 & 8.297 & $\ldots$ & 3.405 & 4.176 & 122,6 & -771 & 6,4 & \\
\hline $\begin{array}{l}1925- \\
1929\end{array}$ & 36.222 & 15.491 & 42,8 & 20.730 & 20.139 & 5.485 & 4.624 & 84,3 & 862 & 6,6 & 24,1 \\
\hline $\begin{array}{l}1930- \\
1934\end{array}$ & 42.993 & 17.934 & 41,7 & 25.059 & 24.976 & 8.456 & 6.446 & 76,2 & 2.011 & 5,1 & 12,5 \\
\hline
\end{tabular}

Fuente: DGOSN (1900-1911, passim) y OSN (1912-1934, passim).

vicio de los empréstitos afectados a las Obras Sanitarias antes de 1914, se llegó en 1927 a superar los 20 millones, un monto prácticamente similar al producto neto disponible. En ello influían los empréstitos externos que entre 1924 y 1927 habían consolidado los adelantos recibidos tempranamente para la expansión de las obras, y en menor medida los títulos de deuda interna que los sucesivos presupuestos venían autorizando a colocar con destino a las obras en las provincias. En la práctica esto recortaba la autonomía del organismo, ya que si bien podía asegurar la explotación sin recursos externos, necesitaba de los fondos de la Tesorería para todos sus programas de inversión.

Un párrafo aparte merece la explotación de las Obras en las provincias, que fue durante dos subperiodos deficitaria (1915-1924) para empezar a arrojar saldos positivos desde 1925 en adelante. Sin embargo los coeficientes de explotación siempre fueron sensiblemente mayores que los de Capital (del orden del 80 por cien en este último periodo) y por otra parte, el monto de ingresos brutos que la totalidad de las ciudades aportaba era 6 veces inferior al que generaba la ciudad de Buenos Aires. 


\section{CONSIDERACIONES FINALES}

En este trabajo hemos examinado algunos aspectos de la evolución de las finanzas públicas en los tres primeros decenios del siglo XX, un periodo signado por la transición hacia un nuevo modelo de estatidad, el del Estado-empresario, que se terminaría de conformar en las décadas de 1930 y 1940 . El contexto estuvo marcado, ante todo, por un crecimiento del aparato estatal y en el nivel del gasto público, orientado prioritariamente a la inversión pública. Este crecimiento distó de ser lineal, y asistió a algunas contramarchas, como en el periodo de la Primera Guerra Mundial. En términos de su participación en el PBI, luego de un retroceso hasta 1919-1920, volvió a ascender hasta ubicarse en niveles muy próximos a los de los mejores años de preguerra. A valores constantes, entre el primer y el último quinquenio del periodo, el gasto total aumentó unas 3,3 veces, en tanto el destinado a obras y trabajos públicos lo hizo 4,6 veces.

Este crecimiento coexistió con una estructura de recaudación tributaria que no cambió sensiblemente a lo largo del periodo, pero que estuvo en condiciones de generar un ingreso creciente, en términos reales (aunque declinante en términos del PBI), ciertamente que con fuertes fluctuaciones que sólo en parte pudieron ser mitigadas por la índole complementaria de ciertos impuestos (los de comercio exterior, los internos). En conjunto los ingresos aumentaron por debajo de los gastos, lo que sentó una de las bases de un sostenido proceso de endeudamiento a todo lo largo del periodo. Este proceso, que en los años previos a la Primera Guerra Mundial alimentó uno de los picos más altos de la inversión pública sobre la base de emisiones de largo plazo en los mercados externos, dio paso con el estallido bélico a formas novedosas. En principio fue la emisión de una deuda flotante, de proporciones hasta entonces no conocidas, colocada crecientemente en el mercado interno, la que permitió sostener el gasto y la inversión en un contexto de derrumbe de los ingresos. Luego sobrevendría un periodo de estabilización y consolidación a mediados de los años veinte, y de renovado acceso a los mercados externos, ahora norteamericanos, hasta que el último pico de inversiones, y subsecuente caída de ingresos, volviera a ser sustentada en una nueva expansión de la deuda interna, sobre todo de corto plazo.

En ese marco, la inversión en ferrocarriles y obras de saneamiento fue la que registró la mayor expansión (unas 6,7 veces entre el primer y último quinquenio), con similares fluctuaciones de conjunto - aún con ciertos defasajes- que el gasto y la obra pública, lo que evidenciaba su comportamiento pro-cíclico.

Los dos quinquenios previos a la Primera Guerra Mundial presentaron la mayor intensidad en esta onda ascendente. No casualmente fue el periodo en el que se organizaron las administraciones autárquicas en las dos áreas examinadas: AGFE en ferrocarriles, OSN en saneamiento urbano. Esto se hizo 
en el marco de sendos programas de expansión de largo aliento que tendían, de un lado, a extender y completar un sistema nacional de ferrocarriles del Estado en todas las provincias y territorios, y del otro, a articular una red de saneamiento a la altura del portentoso desarrollo de la ciudad de Buenos Aires, e inclusivo de todos los núcleos urbanos significativos a lo largo y ancho del país.

La Primera Guerra Mundial obligó a interrumpir una parte de estos proyectos, pero no deja de ser significativo que con la recuperación económica de los tempranos 1920, sobreviniera su reactivación, casi en los mismos términos pensados inicialmente, aunque ahora a cargo de administraciones de otro signo político. Lo mismo puede señalarse a partir de 1930. La consolidación de una noción de estatidad parecería subyacer en estos casos, apuntalando un carácter más orgánico de las estructuras organizacionales que se estaban armando.

En el caso de los Ferrocarriles del Estado esta consolidación estuvo jaqueada por el recurrente déficit de explotación y las dificultades en el mantenimiento de la red, que dieron lugar a reiteradas intervenciones del poder central. En el caso de Obras Sanitarias, por el contrario, el superávit operativo obtenido en las gran urbe porteña sería el sustento para una sólida presencia en todo el territorio nacional. En todo caso las importantes implicancias de ambos tipos de inversiones para el sostenimiento de la vida económica y social en amplias zonas del interior, y de los respectivos organismos autárquicos como herramientas de esta acción estatal, los convertiría en uno de los primeros eslabones en el largo proceso de construcción de ese nuevo Estado-empresario, al que la crisis de 1930 y otros eventos posteriores le terminarían de dar su formato definitivo.

\section{FUENTES}

AGP (1925): Archivo General Parlamentario, «Deuda de los Ferrocarriles del Estado al 31 de diciembre de 1924. Informe presentado por el señor Nemesio Muntaabski», Documentos Varios, Comisión Especial Investigadora de los Ferrocarriles del Estado, H. Cámara de Diputados de la Nación, Buenos Aires.

\section{BIBLIOGRAFÍA}

Aghion, P.; Banerjee, A., y Piketty, T. (1999): «Dualism and macroeconomic volatility». Quaterly Journal of Economics, XXIV: 4, pp. 1359-1397.

ALA (1954): Anales de Legislación Argentina. Años 1889-1919, Buenos Aires.

AYSA (s/f): Aguas y Saneamiento de la Argentina, S. A., The González Library, Buenos Aires.

Ambrosius, G. (1997): «Les entreprises publiques et l'economie sociale du marché de la RFA». Entreprises et Histoire, 16, pp. 63-76. 
Balboa, M. (1972): «El balance de pagos de la República Argentina, 1913-1950». Desarrollo Económico, 45, pp. 151-172.

Bordi de Ragucci, O. (1997): El Agua privada en Buenos Aires, 1856-1892, Buenos Aires.

Bouvier, J. (1978): «Histoire financière et problèmes d'analyse des dépenses publiques». Annales ESC, 33, p. 2.

Bunge, A. (1920): «El costo de vida en 1919». Revista de Economía Argentina, IV: 22, pp. 253-261.

Burgess, R., y STERn, N. (1993): «Taxation and Development». Journal of Economic Literature, XXI, pp. 762-832.

CARAVACA, J. (2008): Estado, economía y economistas. El caso del Impuesto a la Renta en la Argentina, 1890-1932 (tesis de maestría), Universidad de Buenos Aires, Facultad de Ciencias Sociales.

Cavallo, D.; Mundlack, Y., y Domenech, R. (1986): «Estadísticas de la evolución económica de Argentina 1913-1984». IEERAL, Estudios IX: 39, pp. 103-184.

CEPAL (1958): Comisión Económica para América Latina, El Desarrollo Económico de la Argentina, vol. 5: "Algunos estudios especiales y estadísticas macroeconómicas», Santiago de Chile: CEPAL (mimeo).

CibotTi, R., y SierRa, E. (1970): El sector público en la planificación del desarrollo, México, ILPES Siglo XXI.

Comín, F., y Martín Aceña, P. (dirs.) (1991): Historia de la empresa pública en España, Madrid: Espasa-Calpe.

Comín, F., y DíAz Fuentes, D. (2004): La empresa pública en Europa. Una perspectiva histórica, Madrid: Síntesis.

- (2006): «La evolución de la Hacienda Pública en Argentina, España y México, 18201940». XIV International Economic History Congress, Helsinki: IEHA.

Cortes Conde, R. (1989): Dinero, deuda y crisis. Evolución fiscal y monetaria en la Argentina, Buenos Aires: Sudamericana.

Daunton, M. (1996): "Payment and Participation: Welfare and State-Formation in Britain 1900-1951». Past \& Present, 150, pp. 169-216.

Della Paolera, G., y Taylor, A. (2003): A New Economic History of Argentina, Cambridge: Cambridge University Press.

Díaz Alejandro, C. (1981): «Tipo de cambio y términos de intercambio en la República Argentina 1913-1976». CEMA, Serie de Investigaciones, 22.

DíAz Fuentes, D. (1993): Las políticas fiscales de Argentina, Brasil y México durante la Gran Depresión, Madrid: Instituto de Estudios Fiscales.

- (1994): Crisis y cambios estructurales en América Latina. Argentina, Brasil y México durante el periodo de entreguerras, México: Fondo de Cultura Económica.

- (1999): «Models of Growth and Fiscal Policy in Latin America. Fiscal Dependence on Foreign Trade and Tax Reforms in the interwar period», en F. Comín, D. Díaz y E. SCHREMMER, Tax Systems in Historical Perspective: Equity or growth?, Madrid: ICEI, pp. $35-50$.

DiÉGuEz, H. (1972): «Crecimiento e inestabilidad del valor y el volumen físico de las exportaciones argentinas en el periodo 1864-1963». Desarrollo Económico, 46, pp. 334-347.

GuY, D. J. (1979): «La política de Carlos Pellegrini en los comienzos de la industrialización argentina, 1873-1906». Desarrollo Económico (73), Buenos Aires, p. 20.

EFCE: República Argentina, Dirección General de Ferrocarriles, Estadística de los Ferrocarriles en Explotación (Buenos Aires, 1892-1943).

Eichengreen, B. (1995): «Financing Infrastructure In Developing Countries: Lessons From The Railway Age». World Bank Research Observer, 10, pp. 75-91. 
Foreman-Peck, J., y Millward, R. (1994): Public and private ownership of British industry, Oxford: Clarendon Press.

Ferns, H. S. (1966): Gran Bretaña y Argentina en el siglo XIX, Buenos Aires: SolarHachette.

FERreres, O. (2005): Dos siglos de economía argentina (1810-2004), Buenos Aires: Fundación Norte y Sur.

García Heras, R. (1983): «Los ferrocarriles británicos en la Argentina (1928-1943)». Tesis doctoral, Facultad de Humanidades, Universidad Nacional de La Plata.

Gemmell, N., y Morrissey, O. (2005): «Distribution and Poverty Impacts of Tax Structure Reform in Developing Countries: How Little We Know». Development Policy Review, 23: 2, pp. 131-144.

Gerchunoff, P., y AguirRe, H. (2006): «La economía argentina entre la Gran Guerra y la Gran Depresión». Estudios y Perspectivas, Buenos Aires: CEPAL.

GerchunOFF, P., y LLACH, L. (2005): El ciclo de la ilusión y el desencanto. Un siglo de políticas económicas argentinas, Buenos Aires: Ariel.

GeRChUNOFF, P., y SALAZAR, E. (2002): Ilusión o realidad? El crecimiento de la economía argentina durante la década de los 20, Buenos Aires: Instituto y Universidad Torcuato Di Tella.

Giuntini, A. X.; HerTner, P., y NúÑEZ, G. (2004): Urban Growth on Two Continents in the 19th ant 20th Centuries. Technology, Networks, Finance and Public Regulation, Granada: Comares.

Goodwin, P. B. (1974): Los ferrocarriles británicos y la UCR, 1916-1930, Buenos Aires: Ediciones La Bastilla.

Heredia, A. (2008): «El fracaso del proyecto sobre la aplicación del impuesto a la renta durante el gobierno de Yrigoyen». III Jornadas de Investigación de la División Historia, Univ. Nac. de Luján, Dpto. de Ciencias Sociales.

HinRICHS, H. H. (1967): Una teoría general del cambio de la estructura tributaria durante el desarrollo económico, Mexico: CEMLA.

International Monetary Fund (IMF) (1984): Exchange Rate Volatility and World Trade: a study, Washington: IMF.

Lacoste, P. (2000): El Ferrocarril Trasandino, 1872-1984, Santiago de Chile.

LANCiotTi, N. (2007): «Empresas autónomas y grupos de inversión. Las empresas del grupo Morrison en Rosario, Argentina (1890-1930)». Investigaciones de Historia Económica, 8, pp. 109-140.

LEwIS, C. M. (1983): British railways in Argentina 1857-1914. A case study of foreing investment, London: Institute of Latin American Studies, University of London.

López, M. J. (1994): Historia de los ferrocarriles nacionales 1866-1886, Buenos Aires: Lumière.

- (2000): Ferrocarriles, deuda y crisis. Historia de los ferrocarriles en la Argentina de 1887 a 1896, Buenos Aires: Editorial de Belgrano.

MARICHAL, C. (1988a): Historia de la deuda externa de América Latina, Madrid: Alianza.

- (1988b): "Políticas de desarrollo económico y deuda externa en Argentina (18681880)». Siglo XIX. Revista de Historia, III: 5, Monterrey.

MCGN: Contaduría General de la Nación (República Argentina), Memorias (Buenos Aires, 1912-1935).

MH: Ministerio de Hacienda (República Argentina), Memorias (Buenos Aires, 19001911).

Millward, R., y Singleton, J. (1995): The political economy of nationalisation in Britain 1920-1950, Cambridge University Press.

Millward, R. (2005): Private and Public Enterprise in Europe: Energy, telecommunications and transport c.1830-1990, Cambridge University Press. 
MOP: Ministerio de Obras Públicas (República Argentina), Memorias (Buenos Aires, 1898-1935).

Musgrave, R. (1969): Fiscal Systems, New Haven: Yale University Press.

Musgrave, R., y Musgrave, P. (1992): Hacienda Pública. Teórica y aplicada, Madrid: McGraw-Hill.

NewBery, D. (1987): «Taxation and Development», en D. NewBERY y N. STERN (eds.), The Theory of Taxation for Developing Countries, New York: The World Bank-Oxford University Press, pp. 165-204.

O'Connell, A. (1984): «La Argentina en la depresión: los problemas de una economía abierta». Desarrollo Económico, 92, Buenos Aires, pp. 479-513.

OSN: Obras Sanitarias de la Nación, Memoria anual (1912-1934), passim.

OszlaK, O. (1982): La formación del Estado Argentino, Buenos Aires: Editorial de Belgrano.

Palermo, S. A. (2001): The Nation Building Mission: The State-Owned Railways in Modern Argentina (1870-1930), Ph. Diss, State University of New York at Stony Brook.

Peters, E. (1996): Volatility. Chaos and Order in the Capital Market, New York: J. Wiley \& Sons.

Peters, H. (1934): The Foreign Debt of the Argentine Republic, Baltimore.

PREtTo, R. U. (1926): Ferrocarriles del Estado. Formación y desarrollo de la red, Buenos Aires: Dirección General de Ferrocarriles.

Pro Ruiz, J. (2004): "La reforma de la Hacienda Pública decimonónica en España y Argentina». XIX Jornadas de Historia Económica, San Martín de los Andes.

- (2005): Notas sobre la idea de "modernización fiscal», Madrid.

RA (1917): República Argentina, Mensajes y proyectos del Poder Ejecutivo Nacional sobre creación del Banco de la República y emisión de un empréstito interno de \$500.000.000 $m / n$, Buenos Aires.

- (1923a): República Argentina, Deuda pública no consolidada: mensaje del Poder Ejecutivo e informe de la Contaduría General de la Nación.

- (1923b): República Argentina, Proyecto de empréstito interno de mil millones de pesos $m / n$, Buenos Aires.

REgALSKY, A. M. (2002): Mercados, inversores y elites. Las inversiones francesas en la Argentina. 1880-1914, Buenos Aires: Eduntref.

- (2007): «De Buenos Aires a la Nación: la construcción de una empresa pública de saneamiento en la Argentina, 1892-1930». I Congreso Latinoamericano de Historia Económica, Montevideo.

REY, O. (2000): El saneamiento en el área metropolitana, Buenos Aires.

SALAZAR, E. (2004): El crecimiento económico durante la década de los 20: notas para una revisión crítica, Buenos Aires: Instituto Torcuato Di Tella.

SALERno, E. (2003): Los comienzos del Estado empresario: La Administración General de los Ferrocarriles del Estado (1910-1928), Buenos Aires: CEEED-FCE-UBA.

SÁnchez Román, J. A. (2009): "Economic Elites, Regional Cleavages, and the First Attempts at Introducing the Income Tax in Argentina». Hispanic America Historical Review, 89: 2 (may), pp. 253-284 (en prensa).

SCHVARzER, J. (1979): «Empresas públicas y desarrollo industrial en Argentina». Economía de América Latina, 3, pp. 45-68.

SOARES, C. F. (1922): Economía y finanzas de la Nación Argentina, 1916-1922, Buenos Aires.

- (1932): Economía y finanzas de la Nación Argentina, 1922-1932, Buenos Aires.

Solberg, C. (1982): Petróleo y nacionalismo en la Argentina, Buenos Aires: Hyspamérica.

TANZI, V. (1987): "Quantitative Characteristics of The Tax System of Developing Countries», en D. NewBerY y N. STERn (eds.), The Theory of Taxation for Developing Countries, New York: The World Bank-Oxford University Press, pp. 205-241. 
Tilly, Ch. (1975): The Formation of the National States in Western Europe, Princeton: Princeton University Press.

Tornquist, E. y Cía. (1930): Manual of Argentine National, Provincial and Municipal Loans, Buenos Aires.

Villanueva, G. (1903): Memoria de las Obras de Salubridad correspondiente al año 1902, Buenos Aires.

Weber, C., y WildavsKy, A. (1986): A History of Taxation and Expenditure in the Western World, Nueva York: Simon and Schuster.

Wilkins, M. (2003): «Conduits for Long-term Foreign Investment in the Gold Standard Era», en M. Flandreau, C. L. HoltFrerich y H. James (eds.), International Financial History in the Twentieth Century: System and Anarchy, Cambridge: Cambridge University Press, pp. 51-76.

WRIGHT, W. R. (1980): Los ferrocarriles ingleses en la Argentina. Su influencia en el nacionalismo económico, 1854-1948. Buenos Aires: Emecé Editores.

ZaLduendo, E. A. (1975): Libras y Rieles. Las inversiones británicas para el desarrollo de los ferrocarriles en Argentina, Brasil, Canadá e India durante el siglo XIX, Buenos Aires: El Coloquio. 


\section{APÉNDICE}

\section{CUADRO A1}

RENTAS GENERALES. ESTRUCTURA DE LA RECAUDACIÓN, 1910-1935 (en millones de pesos moneda nacional)

\begin{tabular}{|c|c|c|c|c|c|}
\hline Años & $\begin{array}{c}\text { Renta general } \\
\text { corrientes }\end{array}$ & $\begin{array}{c}\text { Renta general } \\
\mathbf{1 9 1 4}\end{array}$ & $\begin{array}{c}\text { Índice de precios } \\
\text { consumidor }\end{array}$ & $\begin{array}{c}\text { PBI Cepal } \\
\mathbf{1 9 1 4}\end{array}$ & $\begin{array}{c}\text { PBI RCC } \\
\mathbf{1 9 1 4}\end{array}$ \\
\hline 1910 & 306,1 & 330,5 & 100,0 & 4.325 & 4.195 \\
\hline 1911 & 313,8 & 335,6 & 101,0 & 4.403 & 4.111 \\
\hline 1912 & 338,7 & 348,4 & 105,0 & 4.762 & 4.888 \\
\hline 1913 & 353,7 & 353,7 & 108,0 & 4.812 & 4.909 \\
\hline 1914 & 250,1 & 250,1 & 108,0 & 4.313 & 4.271 \\
\hline 1915 & 237,2 & 219,0 & 117,0 & 4.336 & 4.596 \\
\hline 1916 & 240,5 & 207,9 & 124,9 & 4.211 & 4.344 \\
\hline 1917 & 241,0 & 178,3 & 146,0 & 3.870 & 3.751 \\
\hline 1918 & 308,3 & 192,4 & 173,0 & 4.580 & 4.748 \\
\hline 1919 & 389,7 & 226,3 & 186,0 & 4.748 & 4.815 \\
\hline 1920 & 493,9 & 262,7 & 203,0 & 5.094 & 4.924 \\
\hline 1921 & 456,5 & 273,2 & 180,5 & 5.224 & 5.096 \\
\hline 1922 & 438,9 & 311,9 & 151,9 & 5.642 & 5.646 \\
\hline 1923 & 524,4 & 379,7 & 149,1 & 6.263 & 6.214 \\
\hline 1924 & 577,6 & 410,5 & 151,9 & 6.752 & 6.764 \\
\hline 1925 & 643,3 & 470,3 & 147,7 & 6.724 & 6.479 \\
\hline 1926 & 619,3 & 466,0 & 143,5 & 7.048 & 6.898 \\
\hline 1927 & 658,4 & 500,7 & 142,0 & 7.548 & 7.445 \\
\hline 1928 & 702,9 & 528,9 & 143,5 & 8.015 & 7.487 \\
\hline 1929 & 718,0 & 546,0 & 142,0 & 8.385 & 7.561 \\
\hline 1930 & 621,4 & 467,6 & 143,5 & 8.038 & 6.947 \\
\hline 1931 & 662,6 & 579,2 & 123,5 & 7.480 & 7.127 \\
\hline 1932 & 727,9 & 709,4 & 110,8 & 7.232 & 6.876 \\
\hline 1933 & 725,1 & 626,7 & 124,9 & 7.572 & 7.038 \\
\hline 1934 & 707,3 & 689,4 & 110,8 & 8.169 & 7.625 \\
\hline 1935 & 800,6 & 736,5 & 117,4 & 8.525 & 8.574 \\
\hline & & & & & \\
\hline
\end{tabular}

Fuentes: Renta general: datos en precios corrientes extraídos de $M H$ (1910-1911) y MCGN (19121932). PBI Cepal \$1914: datos en pesos de 1950 de la serie de CEPAL (1958, p. 3), convertidos mediante los datos de los índices de precios implícitos - Cavallo, Mundlak y Domenech (1986, pp. 130-133) y Ferreres (2005, 204-207) — y de precios de consumidor (véase fuentes de cuadro A3). PBI RCC \$1914: Cortés Conde (1997, pp. 230-231). 


\begin{tabular}{|c|c|c|c|c|c|c|c|}
\hline & in $\frac{\pi}{0}$ & $\begin{array}{l}0 \\
\text { o } \\
\stackrel{+}{n} \\
\text { ñ }\end{array}$ & $\begin{array}{l}0 \\
m \\
m \\
m \\
\infty \\
N\end{array}$ & \begin{tabular}{l}
$\sqrt[n]{n}$ \\
\multirow{\infty}{\sigma}{} \\
$\stackrel{\sigma}{+}$
\end{tabular} & 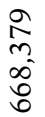 & $\begin{array}{l}0 \\
0 \\
\infty \\
\infty \\
\infty \\
0\end{array}$ & $\begin{array}{l}N \\
\text { in } \\
8 \\
\infty\end{array}$ \\
\hline & de & $\stackrel{\sim}{ \pm}$ & $\stackrel{m}{I}$ & $\stackrel{\infty}{m}$ & $\stackrel{m}{m}$ & 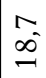 & $\stackrel{\circ}{\circ}$ \\
\hline & $+\overbrace{0}^{\infty}$ & $\stackrel{m}{f}$ & $\stackrel{a}{\infty}$ & $\begin{array}{l}0 \\
\infty \\
\infty\end{array}$ & $\begin{array}{l}\tilde{1} \\
\infty \\
\infty\end{array}$ & $\begin{array}{l}a \\
\infty \\
\stackrel{a}{\simeq}\end{array}$ & $\begin{array}{l}0 \\
0 \\
0\end{array}$ \\
\hline 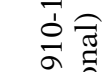 & $\frac{n}{m} d$ & $\stackrel{N}{N}$ & $\begin{array}{l}0 \\
a\end{array}$ & $\stackrel{0}{0}$ & $\overline{0}$ & $\underline{v}$ & $\stackrel{\infty}{i}$ \\
\hline 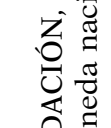 & m & $\begin{array}{l}0 \\
m \\
\text { N }\end{array}$ & $\begin{array}{l}\text { ก̃ } \\
\text { ก̃ } \\
\text { N }\end{array}$ & 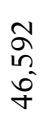 & 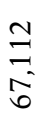 & $\begin{array}{l}n \\
\tilde{m} \\
m \\
=\end{array}$ & $\begin{array}{l}\bar{a} \\
\text { a } \\
\text { a }\end{array}$ \\
\hline 赵 & no & 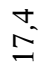 & $\stackrel{0}{\sim}$ & $\stackrel{\nabla}{i}$ & $\mathfrak{n}_{0}^{n}$ & $\begin{array}{l}0 \\
2 \\
-1\end{array}$ & $\stackrel{\infty}{N}$ \\
\hline 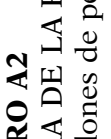 & N & 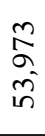 & 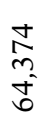 & $\frac{\text { ळे }}{\text { aे }}$ & 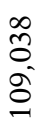 & $\begin{array}{l}0 \\
\infty \\
0 \\
10 \\
m \\
-\end{array}$ & $\begin{array}{l}\stackrel{0}{\infty} \\
m \\
\stackrel{\sim}{ \pm}\end{array}$ \\
\hline 点点 & 㞷 & $\stackrel{0}{0}$ & $\underset{\infty}{+}$ & $\tilde{\sigma}$ & $\hat{m}$ & t. & $\stackrel{0}{0}$ \\
\hline 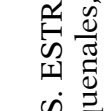 & $=\frac{\dot{\overrightarrow{0}}}{\dot{0}}$ & $\begin{array}{l}8 \\
8 \\
0\end{array}$ & $\begin{array}{l}\stackrel{0}{+} \\
\infty \\
\stackrel{n}{N}\end{array}$ & $\begin{array}{l}\stackrel{0}{+} \\
m \\
\stackrel{n}{+}\end{array}$ & $\begin{array}{l}\overline{8} \\
\text { స̃ }\end{array}$ & $\begin{array}{l}\bar{m} \\
\sim \\
\sim\end{array}$ & $\begin{array}{l}8 \\
8 \\
0\end{array}$ \\
\hline 离 & 盀 & $\begin{array}{l}+ \\
\text { in }\end{array}$ & $\begin{array}{l}0 \\
\text { in }\end{array}$ & $\stackrel{0}{\circ}$ & $\begin{array}{l}0 \\
0 \\
\dot{y}\end{array}$ & i & $\begin{array}{l}0 \\
\dot{m}\end{array}$ \\
\hline 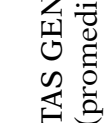 & ت & $\begin{array}{l}\infty \\
= \\
=\end{array}$ & 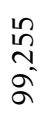 & 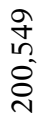 & $\begin{array}{l}\tilde{N} \\
\stackrel{n}{m}\end{array}$ & 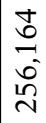 & $\begin{array}{l}\text { J } \\
0 \\
\text { i } \\
\text { i }\end{array}$ \\
\hline 禾 & 능 & $=$ & $\stackrel{\infty}{\sigma}$ & $\begin{array}{l}N \\
\infty \\
\text { in }\end{array}$ & ঠ) & $\begin{array}{l}10 \\
10 \\
+8\end{array}$ & $\stackrel{+}{\circ}$ \\
\hline & $\begin{array}{r}\dot{\overrightarrow{0}} \\
-\dot{0} \\
\dot{0}\end{array}$ & 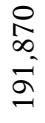 & $\begin{array}{l}\bar{b} \\
\text { ஸे } \\
\text { I }\end{array}$ & $\begin{array}{l}\frac{g}{ \pm} \\
\text { ন }\end{array}$ & \begin{tabular}{l}
$n$ \\
$\infty$ \\
+ \\
$\dot{f}$ \\
\multirow{+}{+}{}
\end{tabular} & $\begin{array}{l}\hat{a} \\
o \\
\hat{o} \\
\text { m } \\
\text { n. }\end{array}$ & $\begin{array}{l}\hat{b} \\
\stackrel{n}{n} \\
\text { ñ }\end{array}$ \\
\hline & 帘 & $\frac{ \pm}{a}$ & $\frac{a}{\frac{a}{1}}$ & 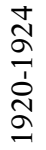 & 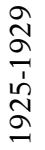 & 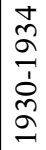 & $\stackrel{n}{a}$ \\
\hline
\end{tabular}




\section{CUADRO A3}

RECURSOS, EROGACIONES Y DÉFICIT DEL SECTOR PÚBLICO NACIONAL (en millones de pesos)

\begin{tabular}{|c|c|c|c|c|c|c|c|}
\hline Años & $\begin{array}{c}\text { Recursos } \\
\text { totales }\end{array}$ & $\begin{array}{l}\text { Erogaciones } \\
\text { totales }\end{array}$ & $\begin{array}{c}\text { Superávit/ } \\
\text { Déficit } \\
\text { (corrientes) }\end{array}$ & $\begin{array}{c}\text { Índice de } \\
\text { precios } \\
(1914=1)\end{array}$ & $\begin{array}{c}\text { Recursos } \\
\text { totales }\end{array}$ & $\begin{array}{c}\text { Erogaciones } \\
\text { totales }\end{array}$ & $\begin{array}{c}\text { Superávit/ } \\
\text { Déficit } \\
\text { (1914) }\end{array}$ \\
\hline 1900 & 163,2 & 162,2 & 1,0 & 0,688 & 237,2 & 235,7 & 1,5 \\
\hline 1901 & 162,6 & 161,7 & 1,0 & 0,732 & 222,2 & 220,9 & 1,3 \\
\hline 1902 & 146,9 & 203,8 & $-56,9$ & 0,732 & 200,7 & 278,5 & $-77,8$ \\
\hline 1903 & 175,4 & 184,9 & $-9,5$ & 0,725 & 242,0 & 255,1 & $-13,0$ \\
\hline 1904 & 199,5 & 194,2 & 5,2 & 0,696 & 286,7 & 279,2 & 7,5 \\
\hline 1905 & 213,6 & 231,3 & $-17,7$ & 0,804 & 265,7 & 287,7 & $-22,0$ \\
\hline 1906 & 231,9 & 229,5 & 2,4 & 0,826 & 280,7 & 277,8 & 2,9 \\
\hline 1907 & 248,1 & 255,1 & $-7,0$ & 0,884 & 280,6 & 288,5 & $-7,9$ \\
\hline 1908 & 256,5 & 256,7 & $-0,2$ & 0,884 & 290,2 & 290,4 & $-0,2$ \\
\hline 1909 & 313,0 & 363,1 & $-50,1$ & 0,926 & 338,0 & 392,1 & $-54,2$ \\
\hline 1910 & 307,6 & 402,5 & $-94,8$ & 0,926 & 332,3 & 434,6 & $-102,4$ \\
\hline 1911 & 330,5 & 409,1 & $-78,6$ & 0,935 & 353,4 & 437,4 & $-84,0$ \\
\hline 1912 & 398,5 & 416,4 & $-17,8$ & 0,972 & 409,9 & 428,3 & $-18,4$ \\
\hline 1913 & 410,0 & 423,9 & $-13,8$ & 1,000 & 410,0 & 423,9 & $-13,8$ \\
\hline 1914 & 289,5 & 408,4 & $-118,8$ & 1,000 & 289,5 & 408,4 & $-118,8$ \\
\hline 1915 & 247,5 & 416,4 & $-168,9$ & 1,083 & 228,5 & 384,5 & $-155,9$ \\
\hline 1916 & 255,0 & 384,7 & $-129,7$ & 1,157 & 220,4 & 332,5 & $-112,1$ \\
\hline 1917 & 254,3 & 389,6 & $-135,3$ & 1,352 & 188,1 & 288,2 & $-100,1$ \\
\hline 1918 & 334,4 & 421,1 & $-86,7$ & 1,602 & 208,7 & 262,8 & $-54,1$ \\
\hline 1919 & 410,9 & 427,9 & $-17,0$ & 1,722 & 238,6 & 248,5 & $-9,9$ \\
\hline 1920 & 559,8 & 487,5 & 72,3 & 1,880 & 297,8 & 259,3 & 38,5 \\
\hline 1921 & 466,0 & 560,6 & $-94,6$ & 1,671 & 278,9 & 335,5 & $-56,6$ \\
\hline 1922 & 463,2 & 614,5 & $-151,3$ & 1,407 & 329,2 & 436,7 & $-107,5$ \\
\hline 1923 & 542,4 & 632,3 & $-89,9$ & 1,381 & 392,8 & 457,9 & $-65,1$ \\
\hline 1924 & 594,1 & 671,2 & $-77,1$ & 1,407 & 422,3 & 477,0 & $-54,8$ \\
\hline 1925 & 659,5 & 713,5 & $-53,9$ & 1,368 & 482,1 & 521,5 & $-39,4$ \\
\hline 1926 & 640,2 & 745,8 & $-105,6$ & 1,329 & 481,7 & 561,2 & $-79,5$ \\
\hline 1927 & 681,4 & 915,8 & $-234,4$ & 1,315 & 518,2 & 696,4 & $-178,2$ \\
\hline 1928 & 725,7 & 884,7 & $-159,0$ & 1,329 & 546,0 & 665,7 & $-119,6$ \\
\hline 1929 & 718,0 & 973,7 & $-255,7$ & 1,315 & 546,0 & 740,4 & $-194,4$ \\
\hline 1930 & 621,5 & 1043,2 & $-421,7$ & 1,329 & 467,6 & 784,9 & $-317,3$ \\
\hline 1931 & 662,6 & 876,3 & $-213,7$ & 1,144 & 579,2 & 766,0 & $-186,8$ \\
\hline 1932 & 727,9 & 935,9 & $-208,0$ & 1,026 & 709,4 & 912,1 & $-202,7$ \\
\hline
\end{tabular}

Fuentes: Cuentas fiscales: $M H$ (1900-1911) y MCGN (1912-1932), passim. Índice de precios: Bunge (1920, pp. 253-261), Cortés Conde (1979, p. 226, y Díaz Alejandro (1981, tabla S3). 


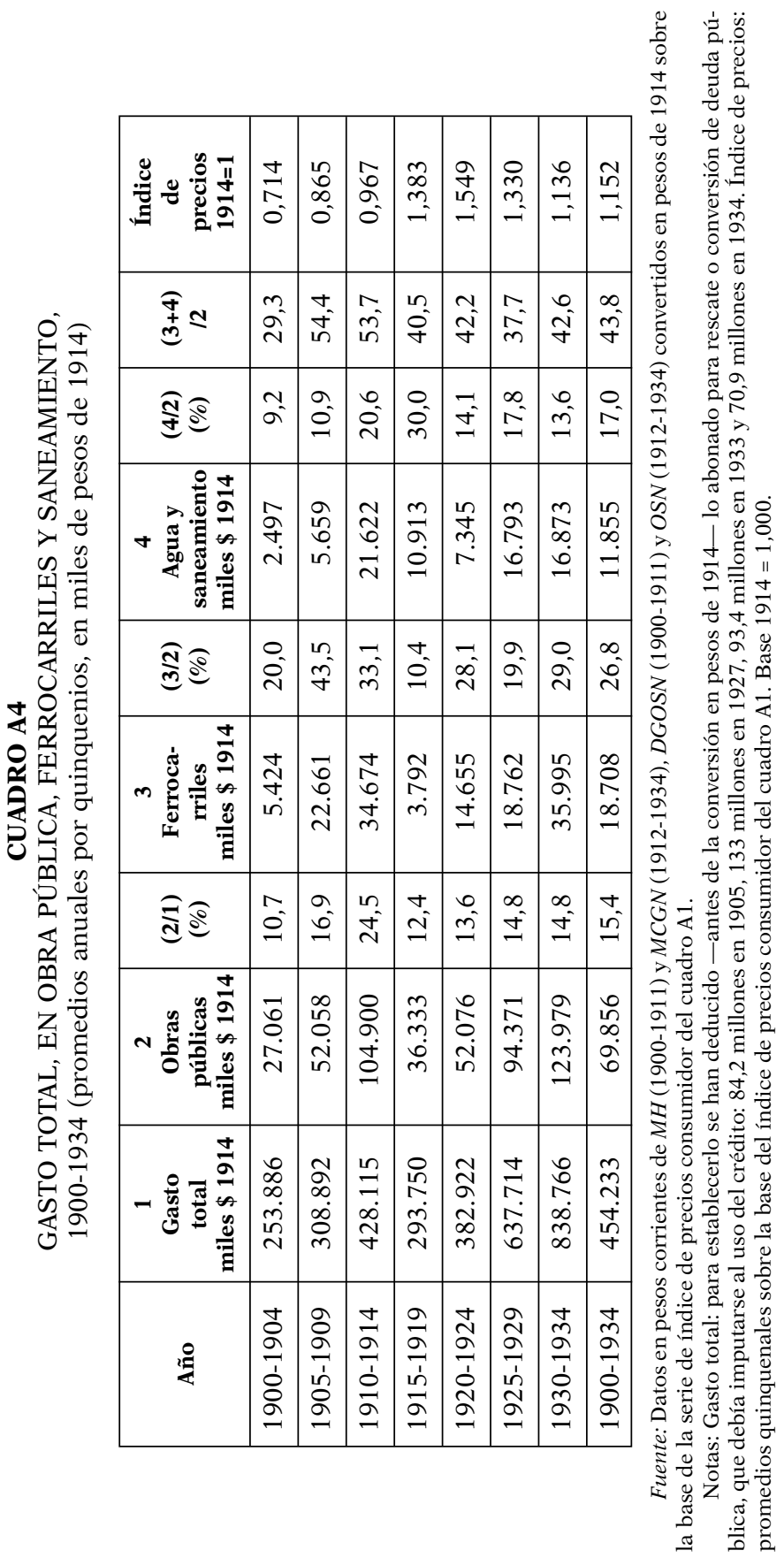




\section{CUADRO A5}

DEUDA PÚBLICA TOTAL, CONSOLIDADA Y FLOTANTE, 1914-1932 (en millones de pesos moneda nacional)

\begin{tabular}{|c|c|c|r|r|r|r|r|c|}
\hline Años & $\begin{array}{c}\mathbf{1}+\mathbf{2} \\
\text { Deuda } \\
\text { total }\end{array}$ & $\begin{array}{c}\text { D. conso- } \\
\text { lidada }\end{array}$ & $\begin{array}{c}\text { 1a } \\
\text { Deuda } \\
\text { externa }\end{array}$ & $\begin{array}{c}\text { 1b } \\
\text { D. interna } \\
\text { en papel }\end{array}$ & $\begin{array}{c}\text { 1c } \\
\text { D. interna } \\
\text { en oro }\end{array}$ & $\begin{array}{c}\text { 2 } \\
\text { D. flotante } \\
\text { + exigible }\end{array}$ & $\begin{array}{c}\text { 2/1+2 } \\
\text { DF/DT } \\
\text { (\%) }\end{array}$ & $\begin{array}{c}\text { DT papel } \\
\text { /D. total } \\
\text { (\%) }\end{array}$ \\
\hline 1913 & $1.279,9$ & $1.238,7$ & 710,1 & 174,1 & 354,5 & 41,2 & 3,2 & 13,6 \\
\hline 1914 & $1.391,8$ & $1.238,7$ & 710,1 & 174,1 & 354,5 & 153,1 & 11,0 & 13,6 \\
\hline 1915 & $1.499,5$ & $1.221,7$ & 703,0 & 169,2 & 349,5 & 277,8 & 18,5 & 19,4 \\
\hline 1916 & $1.639,7$ & $1.242,7$ & 684,5 & 214,2 & 343,9 & 397,0 & 24,2 & 22,2 \\
\hline 1917 & $1.851,0$ & $1.353,2$ & 669,6 & 223,3 & 460,2 & 497,8 & 26,9 & 32,6 \\
\hline 1918 & $1.893,2$ & $1.314,1$ & 642,8 & 219,1 & 452,3 & 579,1 & 30,6 & 35,9 \\
\hline 1919 & $1.865,3$ & $1.285,2$ & 625,1 & 214,2 & 445,9 & 580,1 & 31,1 & 36,3 \\
\hline 1920 & $1.812,1$ & $1.257,4$ & 596,8 & 224,6 & 436,1 & 637,7 & 30,6 & 36,5 \\
\hline 1921 & $1.879,1$ & $1.277,7$ & 573,3 & 218,8 & 487,9 & 709,4 & 32,0 & 37,4 \\
\hline 1922 & $2.279,8$ & $1.294,9$ & 535,7 & 272,6 & 486,6 & 984,9 & 43,2 & 45,6 \\
\hline 1923 & $2.355,0$ & $1.315,8$ & 539,2 & 371,5 & 475,9 & $1.039,2$ & 44,1 & 50,2 \\
\hline 1924 & $2.540,7$ & $1.523,7$ & 687,4 & 457,3 & 464,8 & $1.017,0$ & 40,0 & 50,3 \\
\hline 1925 & $2.497,7$ & $1.743,9$ & 833,2 & 457,3 & 453,4 & 753,8 & 30,2 & 45,0 \\
\hline 1926 & $2.591,6$ & $1.845,7$ & 888,4 & 514,4 & 442,9 & 745,9 & 28,8 & 44,4 \\
\hline 1927 & $2.609,4$ & $2.155,5$ & $1.103,8$ & 621,6 & 430,0 & 453,9 & 17,4 & 40,1 \\
\hline 1928 & $2.770,3$ & $2.268,2$ & $1.111,8$ & 739,8 & 416,6 & 502,1 & 18,1 & 44,8 \\
\hline 1929 & $3.116,2$ & $2.295,1$ & $1.071,4$ & 822,0 & 402,5 & 821,1 & 26,4 & 52,7 \\
\hline 1930 & $3.423,5$ & $2.262,8$ & $1.035,0$ & 840,0 & 387,9 & 1160,7 & 33,9 & 53,3 \\
\hline 1931 & $3.664,8$ & $2.398,1$ & 994,3 & $1.030,1$ & 373,8 & $1.266,7$ & 34,6 & 60,7 \\
\hline 1932 & $3.958,5$ & $2.753,6$ & 942,5 & $1.451,9$ & 359,2 & $1.204,9$ & 30,4 & 65,5 \\
\hline Variación (\%): & & & & & Promedios: & \\
\hline $1913-1923$ & 84,0 & 6,2 & $-24,1$ & 113,4 & 34,2 & 536,1 & 26,9 & 31,2 \\
\hline $1923-1932$ & 68,1 & 109,3 & 74,8 & 290,8 & $-24,5$ & 880,7 & 28,9 & 50,8 \\
\hline $1913-1932$ & 184,4 & 122,3 & 32,7 & 734,0 & 1,3 & 691,2 & 27,8 & 40,0 \\
\hline
\end{tabular}

Fuentes: MCGN (1914-1932, passim), y Soares (1932, pp. 246-250).

Notas: 1. Deuda consolidada: 1a. Externa, 1b. Interna en pesos oro, 1c. Interna en pesos moneda nacional. De estos montos, se hallaban en poder del gobierno 167,4 millones en 1931 y 363 en 1932 . No hay datos previos. 2. Deuda Flotante: incluye la deuda de la Administración General de Ferrocarriles del Estado. 3. DF/DT: Deuda Flotante sobre la Deuda Total (en \%). 4. DT papel/DTotal: deuda en pesos moneda nacional sobre la deuda total (en \%). 
FINANCIAMIENTO E INVERSIÓN PÚBLICA EN LA ARGENTINA EN UN PERIODO...

\section{CUADRO A6}

EVOLUCIÓN COMPARADA DEL VALOR DE LAS EXPORTACIONES, IMPORTACIONES, RENTAS GENERALES E IMPUESTOS

A LAS IMPORTACIONES, 1910-1935

(en millones de pesos corrientes)

\begin{tabular}{|c|c|c|c|c|c|c|c|c|}
\hline Años & $\begin{array}{c}\text { Expor- } \\
\text { taciones } \\
\text { X }\end{array}$ & $\begin{array}{c}\text { Impor- } \\
\text { taciones } \\
\text { M }\end{array}$ & $\begin{array}{c}\text { Términos } \\
\text { de } \\
\text { intercambio } \\
1913=100\end{array}$ & $\mathbf{X}+\mathbf{M}$ & $\begin{array}{l}\text { Imp. } \\
\text { import. } \\
\text { I }\end{array}$ & $\underset{(\%)}{\mathrm{IM} / \mathrm{M}}$ & RG & $\underset{(\%)}{\mathbf{R G} / \mathbf{X}+\mathbf{M}}$ \\
\hline 1910 & 882 & 861 & & 1.743 & 173 & 20,1 & 306 & 17,6 \\
\hline 1911 & 779 & 923 & & 1.702 & 177 & 19,2 & 314 & 18,4 \\
\hline 1912 & 1.129 & 1.007 & & 2.136 & 188 & 18,7 & 339 & 15,9 \\
\hline 1913 & 1.140 & 1.091 & 100,0 & 2.231 & 199 & 18,3 & 354 & 15,9 \\
\hline 1914 & 919 & 891 & 102,1 & 1.810 & 118 & 13,3 & 250 & 13,8 \\
\hline 1915 & 1.266 & 609 & 103,4 & 1.875 & 95 & 15,6 & 237 & 12,7 \\
\hline 1916 & 1.156 & 831 & 89,7 & 1.987 & 105 & 12,6 & 241 & 12,1 \\
\hline 1917 & 1.387 & 813 & 99,4 & 2.200 & 97 & 11,9 & 241 & 11,0 \\
\hline 1918 & 1.738 & 1.090 & 69,3 & 2.828 & 89 & 8,1 & 308 & 10,9 \\
\hline 1919 & 2.050 & 1.362 & 77,1 & 3.412 & 111 & 8,2 & 390 & 11,4 \\
\hline 1920 & 2.664 & 1.919 & 64,2 & 4.583 & 160 & 8,4 & 494 & 10,8 \\
\hline 1921 & 1.584 & 1.710 & 60,4 & 3.294 & 161 & 9,4 & 457 & 13,9 \\
\hline 1922 & 1.584 & 1.710 & 58,6 & 3.294 & 183 & 10,7 & 439 & 13,3 \\
\hline 1923 & 1.743 & 1.923 & 64,3 & 3.666 & 243 & 12,6 & 524 & 14,3 \\
\hline 1924 & 2.100 & 1.931 & 70,1 & 4.031 & 256 & 13,3 & 578 & 14,3 \\
\hline 1925 & 2.100 & 1.931 & 80,3 & 4.031 & 302 & 15,7 & 643 & 16,0 \\
\hline 1926 & 1.824 & 1.569 & 73,4 & 3.393 & 286 & 18,2 & 619 & 18,3 \\
\hline 1927 & 2.324 & 1.668 & 72,0 & 3.992 & 301 & 18,1 & 658 & 16,5 \\
\hline 1928 & 2.428 & 1.902 & 97,0 & 4.330 & 330 & 17,4 & 703 & 16,2 \\
\hline 1929 & 2.196 & 1.959 & 90,4 & 4.155 & 338 & 17,2 & 718 & 17,3 \\
\hline 1930 & 1.414 & 1.680 & 79,1 & 3.094 & 281 & 16,7 & 621 & 20,1 \\
\hline 1931 & 1.475 & 1.174 & 60,3 & 2.649 & 255 & 21,7 & 663 & 25,0 \\
\hline 1932 & 1.305 & 836 & 58,7 & 2.141 & 239 & 28,6 & 728 & 34,0 \\
\hline 1933 & 1.127 & 897 & 56,9 & 2.024 & 257 & 28,7 & 725 & 35,8 \\
\hline 1934 & 1.618 & 1.110 & 68,6 & 2.728 & 248 & 22,4 & 707 & 25,9 \\
\hline 1935 & 1.726 & 1.175 & 70,3 & 2.901 & 272 & 23,2 & 801 & 27,6 \\
\hline
\end{tabular}

Fuentes: Balboa (1972, pp. 152-153 y 163), Diéguez (1972, p. 334), Gerchunoff y Llach (2005, pp. 491492), MH (1910-1911, passim) y MCGN (1912-1935, passim). 


\section{GRÁFICO A1}

VALOR DE LAS EXPORTACIONES, TÉRMINOS DEL INTERCAMBIO

Y VOLUMEN FÍSICO DE IMPORTACIONES (1913-1935)

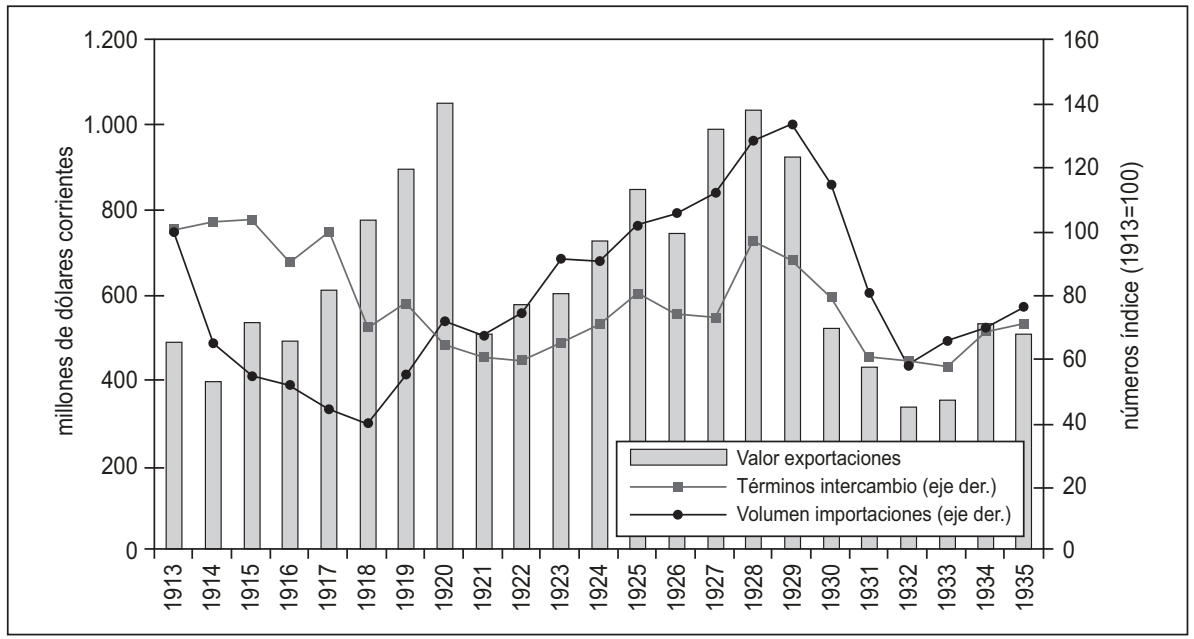

Fuentes: Ver cuadro A6. 